\title{
Sensory Deprivation Disrupts Homeostatic Regeneration of Newly Generated Olfactory Sensory Neurons after Injury in Adult Mice
}

\author{
Shu Kikuta, ${ }^{1,2}$ Takashi Sakamoto, ${ }^{1}$ Shin Nagayama, ${ }^{3}$ Kaori Kanaya, ${ }^{1}$ Makoto Kinoshita, ${ }^{1}$ Kenji Kondo, ${ }^{1}$ \\ Koichi Tsunoda, ${ }^{4}$ Kensaku Mori, ${ }^{2}$ and Tatsuya Yamasoba ${ }^{1}$ \\ ${ }^{1}$ Department of Otolaryngology and 2Department of Physiology, Graduate School of Medicine, University of Tokyo, 7-3-1 Hongo, Bunkyo-ku, Tokyo \\ 113-0033, Japan, ${ }^{3}$ Department of Neurobiology and Anatomy, University of Texas Medical School at Houston, Houston, Texas 77030, and ${ }^{4}$ Department of \\ Artificial Organs and Medical Device Creation, National Institute of Sensory Organs, Tokyo Medical Center, National Hospital Organization, Meguro-ku, \\ Tokyo 152-8902, Japan
}

\begin{abstract}
Although it is well known that injury induces the generation of a substantial number of new olfactory sensory neurons (OSNs) in the adult olfactory epithelium $(\mathrm{OE})$, it is not well understood whether olfactory sensory input influences the survival and maturation of these injury-induced OSNs in adults. Here, we investigated whether olfactory sensory deprivation affected the dynamic incorporation of newly generated OSNs 3, 7, 14, and $28 \mathrm{~d}$ after injury in adult mice. Mice were unilaterally deprived of olfactory sensory input by inserting a silicone tube into their nostrils. Methimazole, an olfactotoxic drug, was also injected intraperitoneally to bilaterally ablate OSNs. The OE was restored to its preinjury condition with new OSNs by day 28. No significant differences in the numbers of olfactory marker proteinpositive mature OSNs or apoptotic OSNs were observed between the deprived and nondeprived sides 0-7 d after injury. However, between days 7 and 28, the sensory-deprived side showed markedly fewer OSNs and mature OSNs, but more apoptotic OSNs, than the nondeprived side. Intrinsic functional imaging of the dorsal surface of the olfactory bulb at day 28 revealed that responses to odor stimulation were weaker in the deprived side compared with those in the nondeprived side. Furthermore, prevention of cell death in new neurons 7-14 $\mathrm{d}$ after injury promoted the recovery of the $\mathrm{OE}$. These results indicate that, in the adult $\mathrm{OE}$, sensory deprivation disrupts compensatory OSN regeneration after injury and that newly generated OSNs have a critical time window for sensory-input-dependent survival 7-14 d after injury.
\end{abstract}

Key words: apoptosis; homeostatic regeneration; olfactory epithelium; olfactory sensory neuron; sensory deprivation

\section{Introduction}

The equilibrium between neuron survival and death helps to maintain and regulate neural circuits. The adult mouse olfactory epithelium (OE) renews itself to maintain a balance between death and generation of olfactory sensory neurons (OSNs). New OSNs, generated from basal progenitor cells, extend axons to the olfactory bulb $(\mathrm{OB})$ to form synaptic connections with mitral and tufted cells (Mori and Sakano, 2011). Therefore, coordinated incorporation of new OSNs may contribute to the homeostasis of a relatively stable OSN population in the $\mathrm{OE}$ and stable olfactory

\footnotetext{
Received June 17, 2014; revised Nov. 12, 2014; accepted Dec. 31, 2014.

Author contributions: S.K. designed research; S.K. performed research; S.K. analyzed data; S.K., T.S., S.N., K. Kanaya, M.K., K. Kondo, K.T., K.M., and T.Y. wrote the paper.

This work was supported by a grant-in-aid for scientific research (C) of the Japan Society for Promotion of Science (to S.K.), a grant-in-aid for scientific research (A) of the Japan Society for Promotion of Science (to K.M.), and grant from the Tokyo Society of Medical Sciences (to S.K.). We thank Atsuko Tsuyuzaki at the University of Tokyo for technical assistance.

The authors declare no competing financial interests.

Correspondence should be addressed to Shu Kikuta, Department of Otolaryngology, Graduate School of Medicine, The University of Tokyo, 7-3-1 Hongo, Bunkyo-ku, Tokyo 113-0033, Japan. E-mail: sh-kiku@m.u-tokyo.ac.jp. DOI:10.1523/JNEUROSCI.2484-14.2015

Copyright $\odot 2015$ the authors $\quad 0270-6474 / 15 / 352657-17 \$ 15.00 / 0$
}

sensory input to the OB; however, the factors allowing new OSNs to maintain this homeostasis are not well known.

Sensory input is important for the maturation and survival of new neurons during development. In the OE, sensory input is known to play a critical role in the survival of immature OSNs during postnatal development (Farbman et al., 1988; Stahl et al., 1990; Brunjes, 1994; Coppola et al., 2006). In striking contrast to this role during postnatal development, the influence of sensory input is far weaker and less clear in the adult $\mathrm{OE}$, which contains primarily mature OSNs (Maruniak et al., 1989, 1990; Brunjes, 1994; Suh et al., 2006). The OE is directly exposed to environmental agents entering the nasal cavity, leaving OSNs prone to injury and degeneration. It is well known that injury-induced loss of mature OSNs in the adult OE causes a prompt and massive regeneration of new OSNs through the proliferation and differentiation of progenitor cells that are subsequently incorporated into olfactory circuits (Schwob, 2002). Therefore, after the injury-induced loss of mature OSNs, the adult OE is transiently composed of newly generated immature OSNs until they later develop into mature OSNs; however, it is not well understood whether olfactory sensory input influences the survival and maturation of these injury-induced, newly generated OSNs in the 
adult OE. This question is of great importance in evaluating the possible role of olfactory sensory inputs in recovering olfactory sensory function after OE injury in adults.

In the present study, we used the olfactotoxic drug methimazole to selectively injure OSNs without damaging the progenitor cells in the OE of mice (Sakamoto et al., 2007). We also inserted a silicone tube into one nostril of each mouse to induce a unilateral nasal occlusion for examining sensory-input-dependent changes in newly generated OSNs. Combining these methods, we determined whether new OSNs generated after injury were functionally incorporated into olfactory circuits in a sensory-input-dependent manner during compensatory tissue regeneration. We found that sensory inputs affected the regeneration of new OSNs after injury. Furthermore, the immature OSNs were highly susceptible to sensory deprivation-induced apoptosis 7-14 d after injury. These results indicate that newly generated OSNs have a critical time window for sensory-input-dependent death or survival and suggest that sensory inputs play a key role in homeostatic regeneration of the OE after injury.

\section{Materials and Methods}

Animals. A total of 70 10-week-old C57BL/6 male mice were used in this study. All experiments were performed using procedures approved by the Experimental Animal Research Committee at the University of Tokyo.

Methimazole administration. To ablate the existing OSNs, mice were intraperitoneally injected on day 0 with methimazole $(75 \mathrm{mg} / \mathrm{kg}$; SigmaAldrich) dissolved in saline (Sakamoto et al., 2007). Mice were perfused with fixative $3,7,14$, and $28 \mathrm{~d}$ after methimazole administration.

Nostril occlusion. Mice were deeply anesthetized with Nembutal and a custom-made $10 \mathrm{~mm}$ silicon tube was inserted into one nostril of each mouse using a previously reported procedure (Cummings et al., 1997). The silicon tube was filled with glue and hair, with the hair slightly protruding from the tube for easier removal from the nostril during experiments (see Fig. 1A). Nostril occlusion was performed 3-6 $\mathrm{h}$ after methimazole administration to avoid influencing progenitor proliferation.

Caspase inhibitor administration. The caspase inhibitor (Wako Biochemicals) was dissolved in a solution containing $90 \%$ distilled water and $10 \%$ dimethyl sulfoxide (DMSO) to a final concentration of $6 \mathrm{mg} / \mathrm{kg}$. The caspase inhibitor was injected on 4 occasions: days 7, 9, 11, and 13 after injury (see Fig. 8). As a control, a solution containing 90\% distilled water and $10 \%$ DMSO was injected in the same manner.

Immunohistochemistry. Mice were perfused intracardially with $4 \%$ paraformaldehyde in $0.1 \mathrm{~m}$ phosphate buffer, decapitated, and postfixed for $24 \mathrm{~h}$ in the same fixative. The nasal tissues, including the OE, were decalcified with $10 \%$ EDTA solution, $\mathrm{pH} 7.0$, and embedded in paraffin. Coronal sections ( $4 \mu \mathrm{m}$ thick) were cut and mounted on silane-coated slides. Deparaffinized sections were autoclaved for $10 \mathrm{~min}$ in Target Retrieval Solution (S1700; Dako) for antigen retrieval. Immunohistochemistry was performed using one of the following antibodies: anti-olfactory marker protein (OMP, goat polyclonal, 1:4000 dilution; Wako Chemicals), anti-activated caspase-3 (rabbit polyclonal, 1:5000; Cell Signaling Technology), anti-Ki-67 (mouse monoclonal, 1:500; BD Biosciences), anti-neutrophil (rat monoclonal, 1:400; Hycult Biotech), and anti-c-fos antibody (rabbit IgG, 1:1000; Santa Cruz Biotechnology). The immunoreaction was detected using the Histofine Simple Stain MAX-PO secondary antibody systems (Nichirei) for anti-OMP (goat), anti-activated caspase-3 (rat), anti-Ki-67 (mouse), anti-neutrophil (rat), and anti-c-fos (rabbit), and the CSA II kit from Dako, a biotin-free tyramide signal amplification system, according to the manufacturers' instructions. Primary antibodies were used for double immunostaining with anti-OMP (anti-OMP antibody, goat polyclonal, 1:4000; Wako Chemicals) and anti-caspase-3 (anti-activated caspase-3 antibody, rabbit polyclonal, 1:5000; Cell Signaling Technology) antibodies. After washing, tissues were incubated with donkey anti-goat Alexa Fluor 488 and donkey antirabbit Alexa Fluor 594 (1:100; Invitrogen) for $1 \mathrm{~h}$ at room temperature.
Analysis. To control for anatomical variations (e.g., concha bullosa) among and within mice, $\mathrm{OE}$ analyses were restricted to the olfactory nasal septum covered by olfactory neuroepithelium for the right and left sides. Three coronal sections located between the caudal OE region and the caudal end of the silicone tube were examined to minimize effects resulting from contact with the silicon tube. Sections were cut at $500 \mu \mathrm{m}$ intervals (see Fig. 1E). The olfactory neuroepithelium contains three major cell types: OSNs, supporting cells, and basal stem cells. We defined the supporting cells as the columnar cells located more apically in the $\mathrm{OE}$ and the basal cells as rectangular cells lying on the lamina propria. The remaining cells were defined as OSNs. The thickness was measured, with the aid of ImageJ software, as the distance from the lamina propria to the surface (Maruniak et al., 1990). The number of OSNs labeled by antiOMP, anti-activated caspase-3, and anti-Ki67 antibodies were analyzed quantitatively using sections with single immunostaining for each antigen and counterstained with hematoxylin. The immunostaining in cells that exceeded two SDs of the mean background intensity for the connective tissue under the lamina propria was considered positive. The numbers of OSNs, supporting cells, and immunostained cells (OMP-, Ki67-, and caspase-3-positive cells, respectively) were counted along the entire length of the nasal septum in each micrographic image for both the right and left sides (open and occluded, respectively). The mean \pm SD of these counts was then calculated for each group per $100 \mu \mathrm{m}$ nasal septum length for the numbers of OSNs, supporting cells, and OMP- and Ki67positive cells; the number of caspase-3-positive cells was quantified per nasal septum length.

To analyze a broader area of the OE, coronal sections of the OE were divided into medial and lateral areas between the most lateral regions of the $\mathrm{OE}$ and the nasal septum. The lateral and medial areas were further divided into upper and lower regions between the most dorsal and ventral edges of the OE, providing four areas in each coronal section of the OE (see Fig. 3I): lateral upper (11), lateral lower (12), medial upper (m1), and medial lower $(\mathrm{m} 2)$. The thickness of the OE and the numbers of OSNs and OMP-positive cells were determined per $100 \mu \mathrm{m}$ length of OE in each of these four areas.

For each $\mathrm{OB}$, one coronal section was selected from the middle region of that $\mathrm{OB}$ and then seven glomeruli were randomly selected in the ventromedial $\mathrm{OB}$ region of the section (see Fig. 4A). A significantly OMPstained area was defined as one in which the staining exceed two SDs of mean background intensity in the external plexiform layer of the $\mathrm{OB}$ (see Fig. 4A; Kikuta et al., 2013). The percentage of the significantly OMPstained area was calculated within a glomerulus by dividing the area of the significantly OMP-stained area by the total area of the glomerulus (OMP-stained area/glomerular area $\times 100)$.

The analysis for immunostained areas was performed using ImageJ software. Respiration patterns were monitored with a thermocouple ( $0.23 \mathrm{~mm}$ diameter, Teflon coated; World Precision Instruments) placed on the nostril opening, recorded to a hard disc with Spike2 software (Cambridge Electronic Design), and analyzed using the Spike2 script language.

Optical imaging of intrinsic signals. The optical imaging device and the procedures for measuring the intrinsic signals were described previously in detail (Uchida et al., 2000). Briefly, intrinsic signals induced by an odorant were imaged under a $705 \mathrm{~nm}$ light (Meister and Bonhoeffer, 2001). Images of the light reflected from the OB surface were collected with a CCD camera (CS8310; TELI) and a tandem-lens macroscope arrangement, and then digitized and stored on a Pentium PC hard disc using a frame-grabber board (Pulsar; Matrox). The CCD camera focused on the dorsal surface of the OB. The images had a spatial resolution of $320 \times 240$ pixels (after $2 \times 2$ binning). The imaged regions were $4.2 \times 3.1$ $\mathrm{mm}$, with a pixel size of $13.1 \mu \mathrm{m}$. The focusing depth of the CCD camera was adjusted to $50-150 \mu \mathrm{m}$ below the OB surface. For each recording trial, data were collected for $8 \mathrm{~s}$ with a frame length of $500 \mathrm{~ms}$ ( 16 frames/ trial). An odorant was presented during frames $4-16$, with a $30 \mathrm{~s}$ interstimulus interval. Odorants were prepared in a glass test tube and diluted in mineral oil. Odorant stimulation was performed by placing the opening of a test tube containing an odorant $10 \mathrm{~mm}$ from a nostril of the mouse. Two stimulus odorants, 2,3,5-trimethyl-3-thiazoline (TMT) and 2-methyl butyric acid (2-MBA), diluted to a 1/10 concentration with 
mineral oil, were used in the experiments (see Figs. $1 C, 5 B$ ) and each odorant was tested at least 4 times per animal. The order of odorant presentation was changed arbitrarily in each experiment.

Quantification of glomerular activity. Optical images were analyzed using IDL (Research Systems) and MetaMorph (Universal Imaging) software. Images of odorant-induced averaged responses were obtained by dividing the magnitude of signals acquired during odorant stimulation (frames 10-16) by that acquired before stimulation (frames 1-4). The differential image was filtered with a Gaussian spatial filter to eliminate nonspecific global darkening and high-frequency noise (high cutoff, $\sigma=20.0 / \mathrm{mm}$; low cutoff, $\sigma=0.2 / \mathrm{mm}$ ). Odor-induced signals in the $\mathrm{OB}$ were calculated by subtracting the prestimulus signals. The responsive areas in the $\mathrm{OB}$ were defined as areas with signals that were at least two SDs above the mean value of the air-induced signals. The mean intensities were defined as the mean values of odor- and pure-airinduced signals along the dorsal surface of the OB. The responsive area and mean intensity for each $\mathrm{OB}$ were analyzed using ImageJ software and were compared between open and occluded sides (see Fig. 1) and between reopened and open sides (see Fig. 5).

Odor-induced c-fos expression in the $O B$. Mice were intraperitoneally injected on day 0 with methimazole and a silicon tube was inserted into one nostril of each mouse on the same day. On day 28 after methimazole administration, mice were housed individually in isolation boxes and supplied with pure air that was deodorized through a charcoal filter. The mice were kept in new cages without food pellets for $4 \mathrm{~h}$ before odor application $(n=5$ mice). Odorants in three categories, aldehydes (propyl aldehyde, $N$-valeraldehyde, $N$-heptylaldehyde, benzaldehyde, and perilla aldehyde), lactones ( $\gamma$-butyrolactone, $\gamma$-heptalactone, $\delta$-hexalactone, $\delta$-nonalactone, and Y-octalactone), and esters (amyl hexanoate, $\mathrm{b}-\boldsymbol{\gamma}$ hexenyl acetate, terpinyl acetate, and isoamyl acetate), were diluted to a $1 / 10$ concentration with mineral oil and a cotton sheet soaked with 100 $\mu \mathrm{l}$ of the diluted solution was placed in a dish. The odor was applied by placing the dish in a cage twice for $1 \mathrm{~h}$ each time with a 10 min interval between placements. After the last odor application, the mice were perfused with fixative and subjected to an analysis of c-fos expression in the OB.

Three coronally sectioned OBs from the rostral tip to the caudal end (excluding the accessary $\mathrm{OB}$ ) that were divided approximately equally among the three regions (rostral, middle, and caudal areas) were selected (see Fig. $5 F$ ). For the analysis, each sampled section was divided into two approximately equal regions from the most ventral to the most dorsal edges of the coronal OB (dorsal and ventral regions; see Fig. 5F). In each region, c-fos-positive cells within the glomerular layer were counted under a fluorescence microscope at a magnification of $200 \times$ and the results were expressed as the number of c-fos-positive cells per square millimeter. The spatial distribution of c-fos-positive cells within the glomerular layer was plotted with the aid of a computerized brain-mapping system (Neurolucida and Stereo Investigator software; MicroBrightField). All mapping was conducted by investigators blinded to the experimental conditions.

Statistical analyses. Statistical analyses were performed with the MannWhitney $U$ test (left vs right side; open vs occluded side; reopened vs open side; after injury vs after saline administration; after methimazoleinduced injury and unilateral nostril occlusion vs after methimazoleinduced injury only; see Figs. $1 G-I, K, 2 C-E, G, 3 C-E, G, J, K, L, 4 C, F, 5 C$, $G, I, J, 6 A, B, D, 7 A, B$ ), and the Steel-Dwass test (for air, TMT, and 2-MBA, see Fig. $5 D$; for 7, 14, and $28 \mathrm{~d}$ after methimazole-induced injury and unilateral nostril occlusion, see Fig. $7 D$ ). The error bars indicate mean \pm SD. A $p$-value $<0.05$ was considered statistically significant.

\section{Results \\ Sensory deprivation for $\mathbf{2 8} \mathrm{d}$ does not induce histological changes in normal OSNs}

We first investigated whether unilateral nostril occlusion affected the responses of the $\mathrm{OB}$ to odorant stimulation. The silicone tube was carefully inserted into the rostral part of the unilateral nasal cavity to abolish nasal airflow (occluded side, 3 and $28 \mathrm{~d}$ after silicone tube insertion; Fig. $1 A, B$ ) without affecting airflow in the opposite nostril (open side, 3 and $28 \mathrm{~d}$ after silicone tube insertion; Fig. $1 B$ ). To rule out the possibility that odor stimulation through the retronasal pathway via the open nostril might have activated OSNs on the occluded side, we examined odorantevoked neural activity on the dorsal surface of the open and occluded sides of the OB using optical imaging (Fig. 1C). The glomeruli in the $\mathrm{OB}$ are grouped into two domains, dorsal and ventral, and the dorsal domain is further divided into the DI and DII domains according to the odorant receptor types expressed (Tsuboi et al., 2006; Kobayakawa et al., 2007). We selected TMT and 2-MBA as stimulus odorants because TMT preferentially activates glomeruli in the DII domain, whereas 2-MBA preferentially activates glomeruli in the DI domain on the dorsal surface of the OB (Kobayakawa et al., 2007). We observed that the occluded $\mathrm{OB}$ failed to show clear responses to odor stimulation between days 3 and 28 after silicone tube insertion (Fig. 1C), whereas the open $\mathrm{OB}$ showed clear responses to TMT and 2-MBA during that same period (Fig. 1C). Although optical mapping of neural activity in the $\mathrm{OB}$ was limited to the dorsal surface, these results confirmed that the silicone tube selectively disrupted odor-induced neural activity on the occluded side and that this sensory deprivation persisted over a long period.

Using the inserted silicone tube method, we then investigated whether sensory deprivation affected the survival and arrangement of the existing OSNs in the OE under normal conditions without injury (Fig. 1D). To avoid any effects due to the silicone tube contacting the nasal mucosa, we selected three coronal sections from the caudal OE separated by $500 \mu \mathrm{m}$ (small arrows, Fig. $1 E)$. The representative $\mathrm{OE}$ was obtained from the occluded nostril side 3, 7, 14, and $28 \mathrm{~d}$ after the tube insertion (Fig. $1 F$ ). The OE thickness, number of OSNs (per $100 \mu \mathrm{m}$ length of OE in the section), and number of supporting cells (per $100 \mu \mathrm{m}$ length of $\mathrm{OE}$ in the section) were not significantly different between the open and occluded sides at any time examined (Fig. 1G-I). Figure $1 J$ shows representative images of slices stained with an antibody against OMP, a molecular marker for mature OSNs. We observed that a majority of the OSNs were OMP-positive from 3 to $28 \mathrm{~d}: 3 \mathrm{~d}, 83.6 \pm 11.5 \%$ open and $86.6 \pm 10.6 \%$ occluded; $7 \mathrm{~d}$, $81.8 \pm 17 \%$ open and $88.1 \pm 18.6 \%$ occluded; $14 \mathrm{~d} 80.5 \pm 8.9 \%$ open and $80.6 \pm 7.9 \%$ occluded; $28 \mathrm{~d}, 81.6 \pm 13.1 \%$ open and $82.4 \pm 12.8 \%$ occluded (OMP-positive cells/total OSNs $\times 100$; mean \pm SD; Fig. $1 J, K)$. No difference in the number of OMPpositive cells was detected between the open and occluded sides (d 3, $p=0.63 ; \mathrm{d} 7, p=0.86 ; \mathrm{d} 14, p=0.34 ; \mathrm{d} 28, p=0.53$; Mann-Whitney test; Fig. $1 K$ ). These results indicate that, under normal uninjured conditions, the $\mathrm{OE}$ contains primarily mature OMP-positive OSNs and sensory deprivation for $28 \mathrm{~d}$ after the tube insertion does not induce histological or cell composition changes, consistent with a previous report (Maruniak et al., 1989).

\section{Newly generated OSNs compensate for methimazole-induced loss of OSNs within $28 \mathrm{~d}$}

Methimazole, an olfactotoxic drug, disrupts existing OSNs nearly evenly throughout the $\mathrm{OE}$ by activating the apoptotic cascade in OSNs (Sakamoto et al., 2007). Because progenitor basal cells in the OE remained intact after methimazole-induced injury, they produce the newly generated OSNs and the OE returns to its preinjury level by $1-2$ months. To examine in detail the repair process through the incorporation of newly generated OSNs after injury, we observed histological changes in the $\mathrm{OE} 3,7,14$, and $28 \mathrm{~d}$ after methimazole administration (saline was administered in control mice; Fig. 2A). 
A
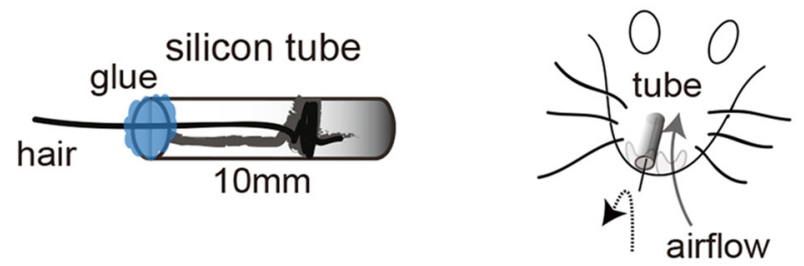

B

d3 after silicon tube insertion

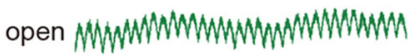

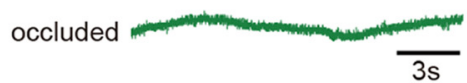

d28 after silicon tube insertion open WWWWMWMWMWWMWM

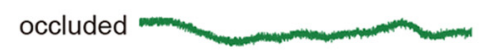

C

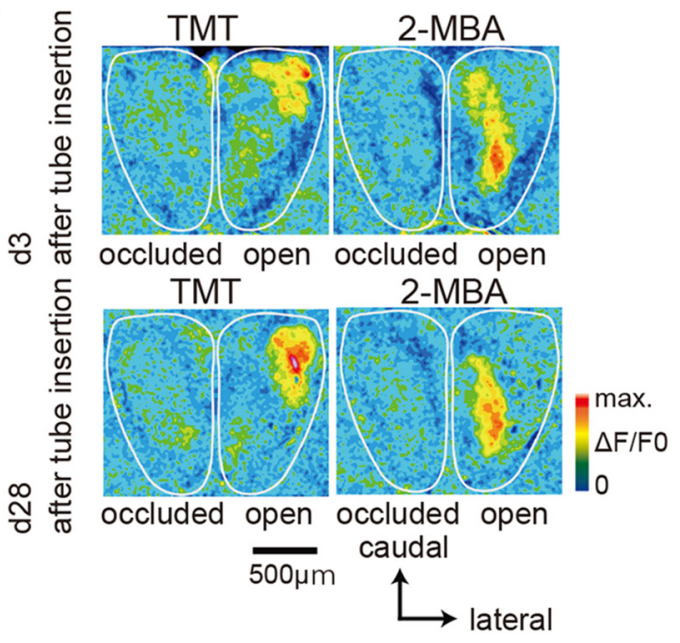

D

E 3D-image of the nose

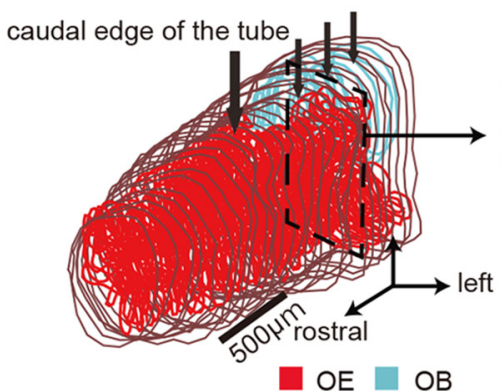

right

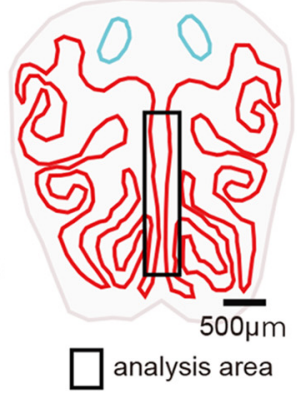

$\mathbf{F}$

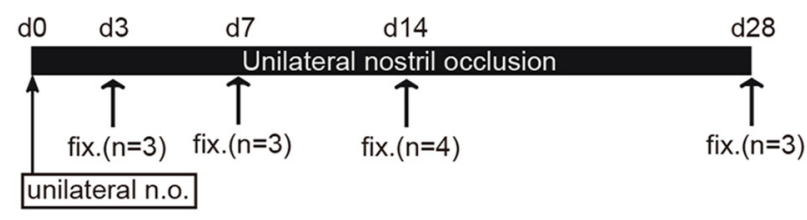

G
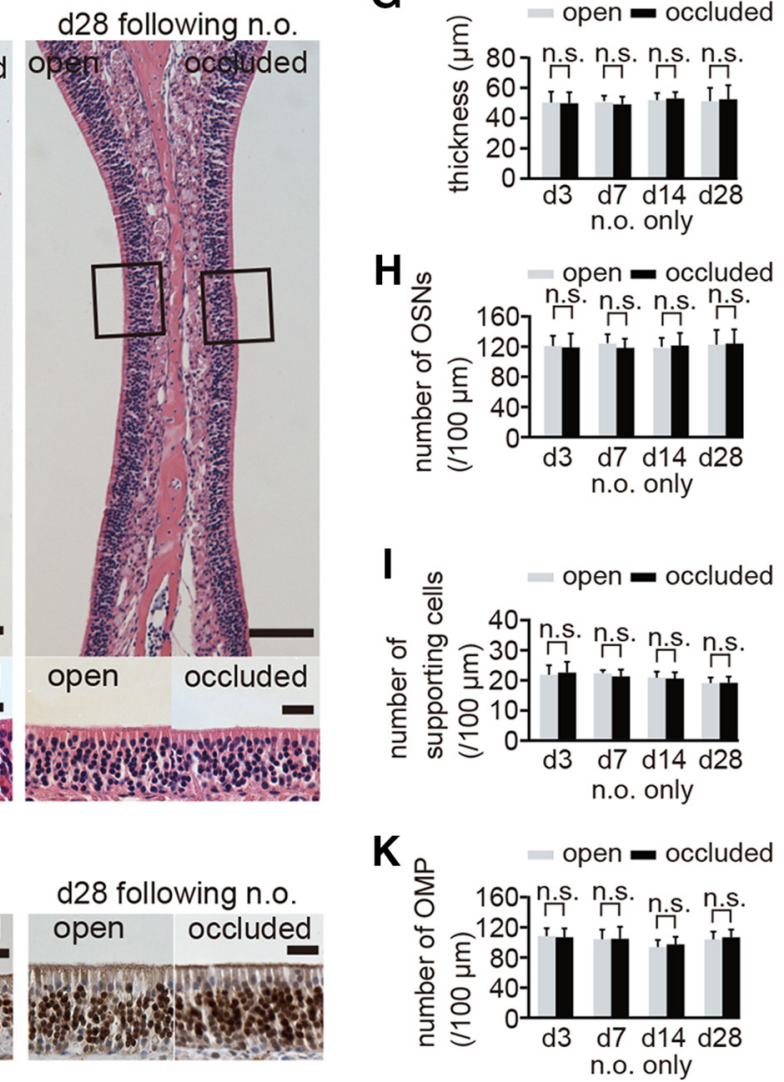

d28 following n.o. apen occluded

$\mathbf{J}$

d3 following n.o. open occluded d7 following n.o.

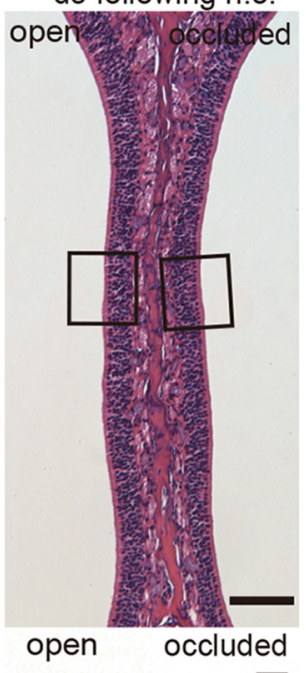

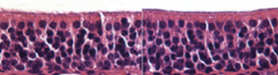

d14 following n.o.
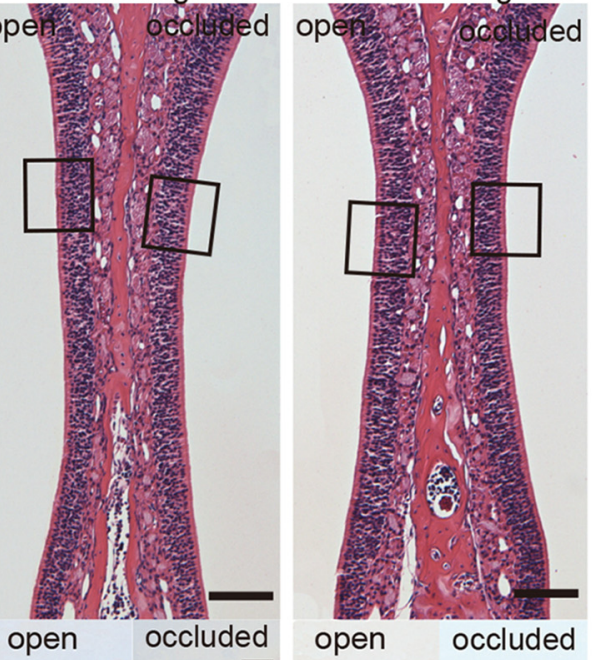
open

occluded

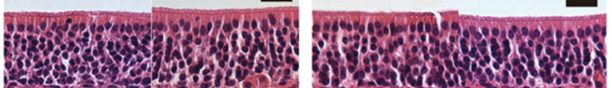

d7 following n.o.

d14 following n.o. open occluded open occluded open occluded

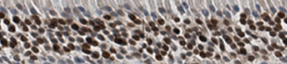


Three days after the methimazole-induced injury, the sensory neuron layer above the basal cell layer was absent and we could not identify residual OSNs and supporting cells, indicating that methimazole administration did not injure basal cells but resulted in the total loss of OSNs and supporting cells (Fig. 2B-E). Seven days after methimazole-induced injury, the OE thickness and the numbers of OSNs and supporting cells increased without significant differences between left and right sides (thickness, $p=$ 0.14 ; number of OSNs, $p=0.42$; number of supporting cells, $p=$ 0.82; Mann-Whitney test; Fig. 2C-E). No OMP-positive cells were identified at this stage (day 7 in Fig. $2 F, G$ ).

Fourteen days after methimazole-induced injury, the $\mathrm{OE}$ thickness and number of OSNs were restored to control levels, that is, those levels observed after saline administration (thickness, Mann-Whitney test between day 14 after injury and day 28 after saline administration, $p=0.57$; number of OSNs, MannWhitney test between day 14 after methimazole-induced injury only and day 28 after saline administration, $p=0.59$; Fig. $2 C, D)$. However, only half of the OSNs differentiated into mature OMPpositive cells on day 14 after injury (Fig. $2 F, G$ ) and there were significantly fewer mature OSNs compared with those after saline administration (number of OMP-positive cells, Mann-Whitney test between day 14 after methimazole-induced injury and day 28 after saline administration, $p<0.001$; Fig. $2 G$ ). These results indicate that newly generated OSNs begin to mature at 7-14 d after injury, but that repair by newly generated OSNs is incomplete.

Twenty-eight days after methimazole-induced injury, in addition to the recovery of the tissue thickness, the numbers of OSNs and OMP-positive cells in the OE were restored to those of control levels after saline administration (number of OMPpositive cells, Mann-Whitney test between day 28 after methimazole-induced injury only and day 28 after saline admin-

$\leftarrow$

Figure 1. Nostril occlusion for $28 \mathrm{~d}$ induces no histological changes in uninjured olfactory epithelium. $\boldsymbol{A}$, Method for unilateral nostril occlusion. Left, Schematic diagram of a $10 \mathrm{~mm}$ silicone tube. A hair protrudes from the tube to confirm silicone tube insertion and the inner cavity of the silicon tube is packed with glue. Right, Schematic diagram of the unilateral nostril occlusion method. $\boldsymbol{B}$, Nasal airflow on days 3 (d 3 ) and 28 (d 28) after silicone tube insertion for both open (top) and occluded sides (bottom). The nasal airflow on days 3 and 28 after silicone tube insertion is completely abolished on the occluded side but remains unaffected on the open side. Scale bar, 3 s. C, Images of the dorsal surface of the olfactory bulb 3 and $28 \mathrm{~d}$ after silicone tube insertion on both occluded (left) and open sides (right). Top image shows odorant-induced intrinsic imaging with TMT and 2-MBA $3 \mathrm{~d}$ after silicone tube insertion on both the occluded (left) and open sides (right); bottom image shows both occluded (left) and open sides (right) on day 28 after silicone tube insertion. The odor-induced signals are detected in the open side, but clear signals are not observed in the occluded side on days 3 and 28 after silicone tube insertion. Scale bar, $500 \mu \mathrm{m}$. D, Time course and experimental design. Unilateral nostril occlusion (unilateral n.o.) was performed on day 0 and perfusion with a fixative (fix.) was conducted on days $3(n=3$ mice), $7(n=3), 14(n=4)$, or $28(n=3)$ after unilateral nostril occlusion. $\boldsymbol{E}$, Analyzed area in the $\mathrm{OE}$. Left, $3 \mathrm{D}$ reconstructed mouse nose. Red area shows $\mathrm{OE}$ and blue shows $\mathrm{OB}$. Bold arrow indicates the caudal edge of the silicone tube; three small arrows indicate the positions of the selected coronal sections. Right, Coronal section from the three selected coronal sections of the $\mathrm{OE}$. Rectangle shows nasal septum, which was the area analyzed. Scale bar, $500 \mu \mathrm{m}$. $\boldsymbol{F}$, Photomicrographs of representative coronal sections through the nasal septum on days $3,7,14$, and 28. Top, Lowest magnification; bottom, higher magnification of that portion of the $0 \mathrm{E}$ in the top images captured at the squares. Left $0 \mathrm{E}$ corresponds to open side and right $0 \mathrm{E}$ occluded side. Scale bars, $100 \mu \mathrm{m}$ at lower magnifications, $20 \mu \mathrm{m}$ for the magnified views. G-I, Thickness of the $0 \mathrm{E}(\boldsymbol{G})$, number of OSNs $(\boldsymbol{H})$, and number of supporting cells $(\boldsymbol{I}) 3,7,14$, and $28 \mathrm{~d}$ after unilateral nostril occlusion. Significant changes are not observed histologically during the sensory deprivation over $28 \mathrm{~d}$ (n.S., not significant, Mann-Whitney test). J, Photomicrographs of representative coronal sections through the nasal septum stained with anti-0MP antibody on days $3,7,14$, and 28 after unilateral nostril occlusion. Brown cells stained by DAB correspond to OMP-positive cells. Scale bar, $20 \mu \mathrm{m}$. $\boldsymbol{K}$, Number of OMP-positive cells 3, 7, 14, and $28 \mathrm{~d}$ after unilateral nostril occlusion. istration, $p=0.25$; Fig. $2 F, G)$. These observations indicate that the tissue recovery in the $\mathrm{OE}$ is completed within $28 \mathrm{~d}$ after the methimazole-induced injury.

Sensory deprivation induces incomplete replacement of OSNs in the OE due to fewer newly generated OSNs during recovery from injury

We next investigated whether the replacement of newly generated OSNs after the methimazole-induced injury was sensoryinput dependent. The experimental design is shown in Figure $3 \mathrm{~A}$. On day 0, 13 mice received intraperitoneal injections of methimazole together with unilateral nostril occlusions. As shown in Figure 3, $B-E$, until day 7 after injury, there were no significant differences between the open and occluded sides in the thickness of the OE or the numbers of OSNs and supporting cells (thickness, $p=0.35$; number of OSNs, $p=0.5$; number of supporting cells, $p=0.19$; Mann-Whitney test). On days 14 and 28, the OE was significantly thinner and significantly fewer OSNs were observed on the occluded side compared with the open side (thickness: day $14, p<0.001$, day $28, p<0.05$; number of OSNs: day 14 , $p<0.001$, day 28, $p<0.05$; number of supporting cells: day 14 , $p=0.3$, day 28, $p=0.19$; Mann-Whitney test; Fig. $3 C-E$ ).

Airflow through the contralateral (open) side increases after ipsilateral nostril occlusion (Kikuta et al., 2008). Therefore, increased airflow in the open side may facilitate OSN regeneration and result in differences in the thickness and number of OSNs between the open and closed sides. Therefore, any observed difference might be due to the facilitation of OSN regeneration in the open side, the partial suppression of OSN regeneration in the occluded side, or both. To examine these possibilities, we compared the structural organization of the OE between the two conditions, that is, methimazole-induced injury plus unilateral nostril occlusion (injury + n.o.) and methimazole-induced injury without nasal occlusion (injury only) (Fig. $3 C-E$ ). We found no significant difference between the two conditions in the thickness or number of OSNs on the open side on days 14 and 28 (thickness: day $14, p=0.96$; day $28, p=0.67$; number of cells: day $14, p=0.57$; day 28, $p=0.72$; number of supporting cells: day 14 , $p=0.31$; day 28, $p=0.38$; Mann-Whitney test; Fig. 3C-E). These results argue against the idea that the increased airflow facilitates OSN regeneration on the open side and suggest that the differences between the open and occluded sides result from the partial suppression of OSN regeneration on the occluded side.

Figure $3 F$ shows representative images of the nasal septum stained with the anti-OMP antibody. The OMP-positive cells were not observed 3 and $7 \mathrm{~d}$ after methimazole-induced injury with unilateral nostril occlusion (Fig. $3 F, G$ ). However, on day 14, OMP-positive cells emerged in both the open and occluded sides (Fig. $3 F, G$ ). Although the number of OMP-positive cells in the open side did not differ from that after methimazole-induced injury without nostril occlusion on day 14 ( $p=0.09$, MannWhitney test; Fig. $3 G$ ), significantly fewer OMP-positive cells were observed on the occluded side compared with those in the open side in mice with both methimazole-induced injury and nostril occlusion ( $p<0.001$, Mann-Whitney test; Fig. $3 G$ ). On day 28, the number of OMP-positive cells in the open side was restored to the level observed after injury without nostril occlusion $(p=0.12$, Mann-Whitney test; Fig. $3 G)$. In contrast, the number of OMP-positive cells in the closed side was significantly lower than that in the open side $(p<0.001$, Mann-Whitney test; Fig. $3 G)$. These results indicate that sensory deprivation results in incomplete recovery of the OE, with fewer newly generated OSNs. 
A

a. methimazole administration

b. saline administration
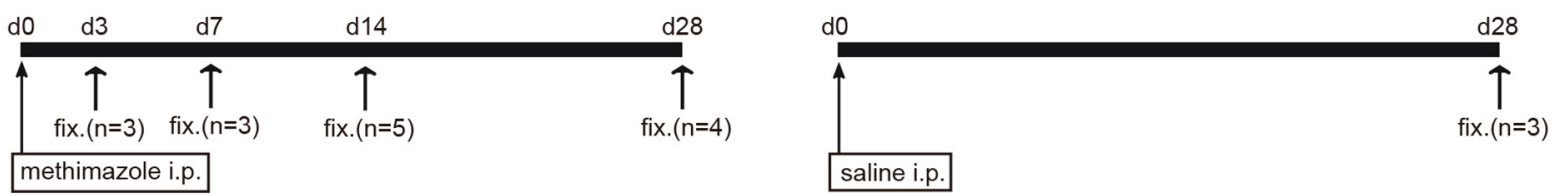

\section{B}

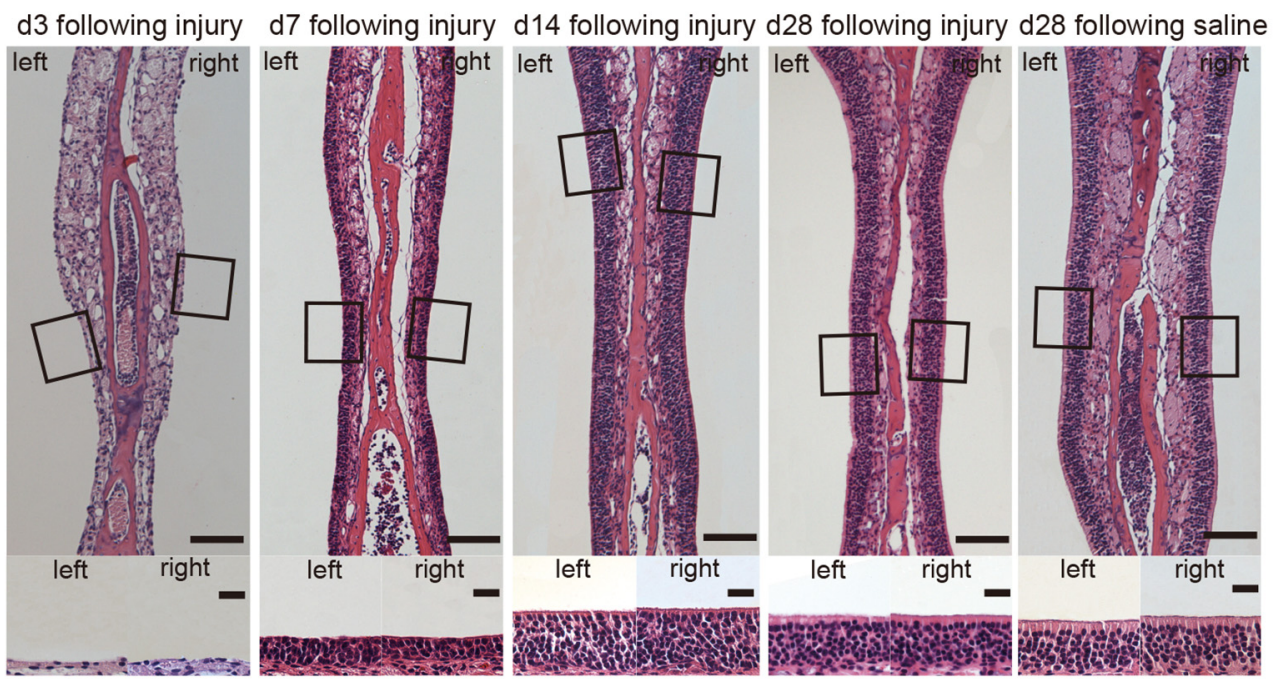

$\mathbf{F}$

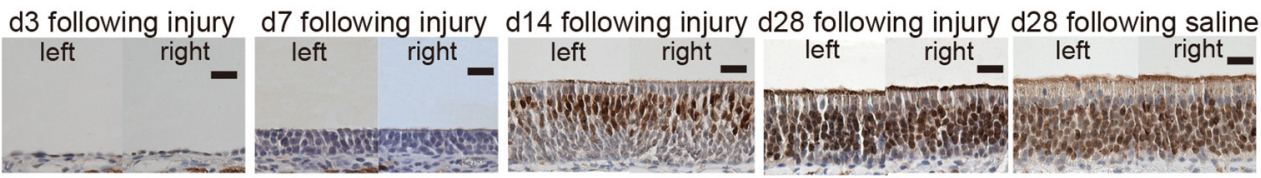

C

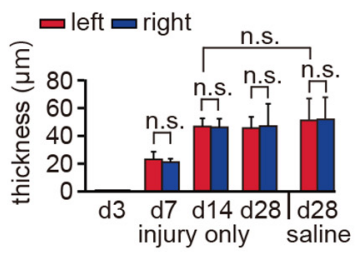

D

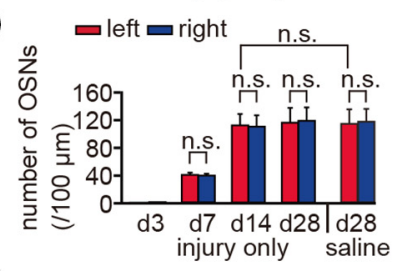

E
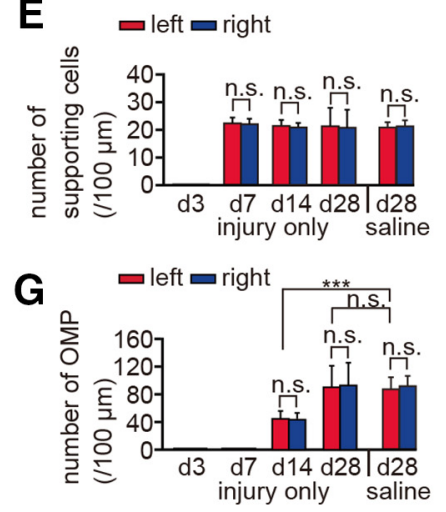

Figure 2. Existing OSNs through the nasal septum are disrupted by methimazole administration but recover to preinjury states within $28 \mathrm{~d}$. $\boldsymbol{A}$, Time course of the experimental design after methimazole (a) and saline (b) administration. Methimazole and saline were administered by intraperitoneal (i.p.) injections on day 0. Fixation (fix.) was performed on days 3 (d3), 7 (d7), 14 (d14), and 28 (d28) after methimazole administration and on day 28 (d28) after saline administration. $\boldsymbol{B}$, Photomicrographs of representative coronal sections through the nasal septum on days 3, 7, 14, and 28 after methimazole administration. Top, Lower magnification; bottom, higher magnification views of the portion of the 0 E in top photographs outlined by the square. Left side of the 0 E in the image corresponds to the left nostril and the right side of the 0 E image corresponds to the right nostril. Scale bar, $100 \mu \mathrm{m}$ at lower magnification, $20 \mu \mathrm{m}$ at higher magnification. $\mathbf{C}-\boldsymbol{E}$, Thickness of the $0 E\left(\boldsymbol{C}\right.$, number of $\left.0 \mathrm{SNs}_{\mathbf{D}} \boldsymbol{D}\right)$, and number of supporting cells $(\boldsymbol{E})$ on days $3,7,14$, and 28 after methimazole administration and on day 28 after saline administration. 0 nday 28 after methimazole administration, the thickness of the $\mathrm{OE}$ and the number of $\mathrm{OSN}$ s are restored to those levels observed after saline administration (n.s., not significant; Mann-Whitney test). $\boldsymbol{F}$, Photomicrographs of representative coronal sections stained with anti-0MP antibody through the nasal septum 3,7, 14, and $28 \mathrm{~d}$ after methimazole administration, and $28 \mathrm{~d}$ after saline administration. Left images, left nostril; right images, right nostril. Scale bar, $20 \mu \mathrm{m}$. G, Numbers of OMP-positive cells on both left and right sides on days 3, 7, 14, and 28 after methimazole administration and on day 28 after saline administration. On day 14 after methimazole-induced injury, the number of OMP-positive cells is significantly reduced compared with that on day 28 after saline administration $\left({ }^{* * *} p<0.001\right.$, Mann-Whitney test), whereas, on day 28 after methimazole administration, the number of OMP-positive cells is restored to that observed on day 28 after saline administration (n.s., not significant; Mann-Whitney test).

The silicone tube occluded the nasal cavity and blocked nasal airflow. This occlusion may block the mucous clearance of inhaled pathogenic antigens and result in topical inflammation of the closed nasal epithelium that suppresses the generation of new OSNs and differentiation into mature OSNs (Ekdahl et al., 2003; Monje et al., 2003). To investigate the possibility of topical inflammation, we examined the infiltration into the $\mathrm{OE}$ of neutrophils, a predominant inflammation marker cell (Fig. $3 H$ ). Neutrophils were abundantly observed in the bone marrow (Fig. $3 \mathrm{H}$, left), whereas we could not detect neutrophils infiltrating the $\mathrm{OE}$ in any section of the occluded or open sides (Fig. $3 \mathrm{H}$, right). These results exclude the possibility that the incomplete OSN regeneration observed after unilateral nostril occlusion is due to topical inflammation in the nasal cavities.
We next investigated whether the incomplete OSN regeneration after sensory deprivation was a general phenomenon applicable to the entire OE. A representative coronal section of the whole OE on day 28 after injury is shown in Figure 3I, left. Figure $3 I$, right, shows images obtained at higher magnification from four OE regions (Fig. 3I, right: 11, lateral upper; 12, lateral lower; $\mathrm{m} 1$, medial upper; $\mathrm{m} 2$, medial lower). For each of the four regions within the $\mathrm{OE}$ (per $100 \mu \mathrm{m}$ length of the $\mathrm{OE}$ in the section), the OE was thinner and there were significantly fewer OSNs and OMP-positive cells on the occluded side compared with the open side (thickness: $11, p<0.001 ; 12, p<0.01 ; \mathrm{m} 1, p<0.001 ; \mathrm{m} 2, p<$ 0.05 ; total, $p<0.001$; number of OSNs: 11, 12, and $\mathrm{m} 1, p<0.001$; $\mathrm{m} 2, p<0.05$; total, $p<0.001$; number of OMP-positive cells: all four regions and total, $p<0.001$; Mann-Whitney test; Fig. 3J-L). 
A

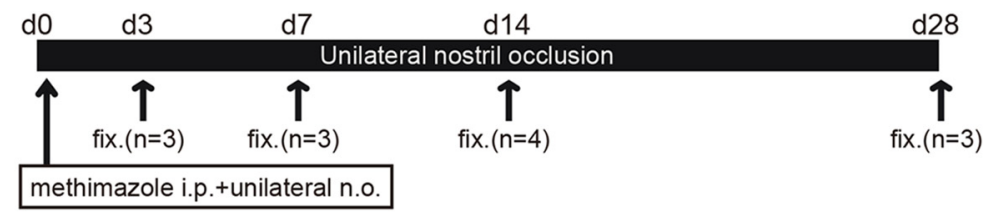

B

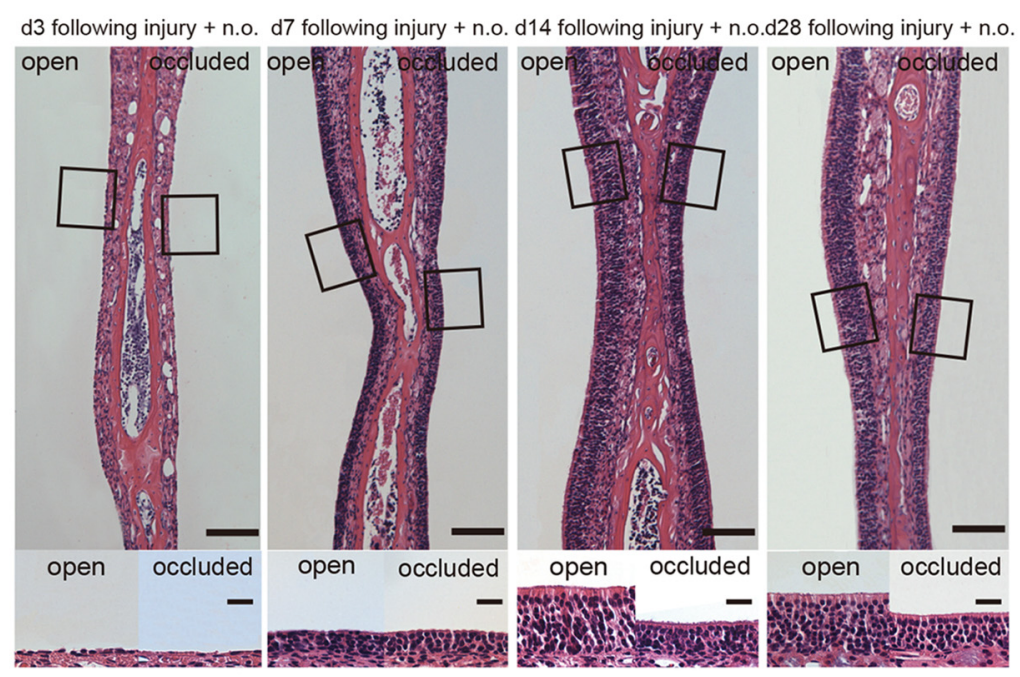

$\mathbf{F}$

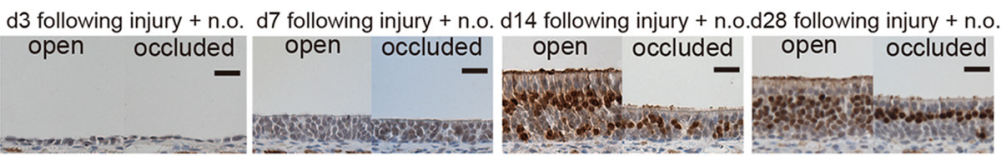

H
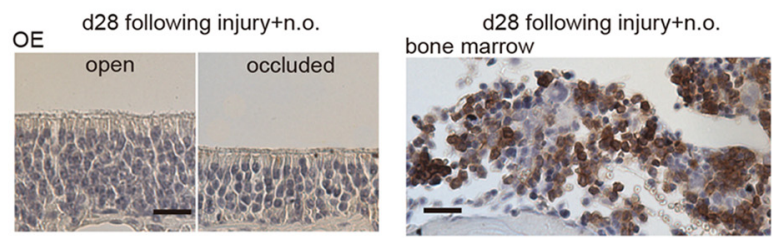

\section{I}

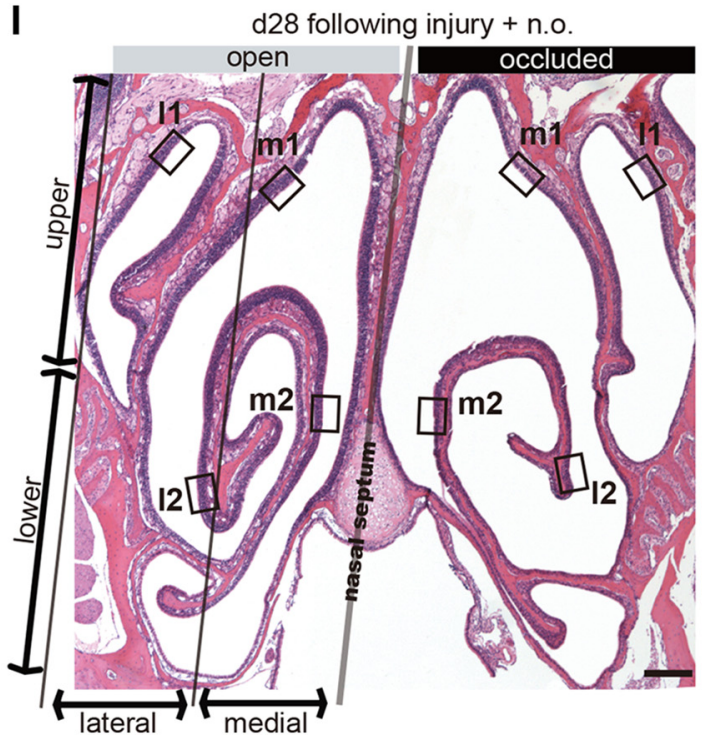

C

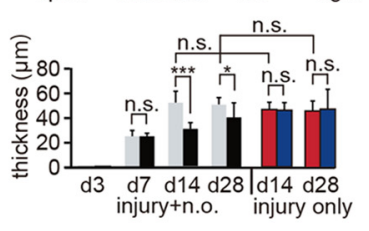

D

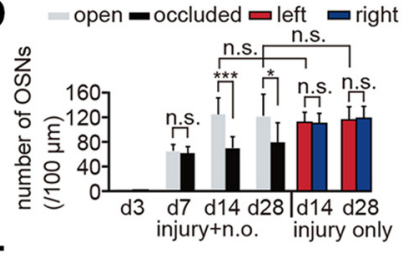

E

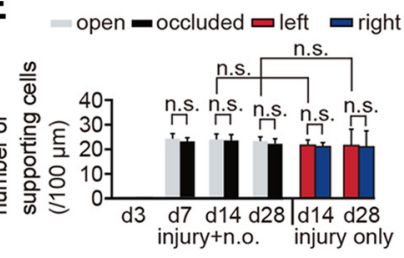

G

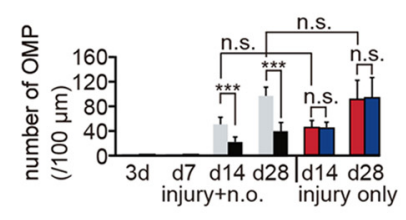

$\mathbf{J}$

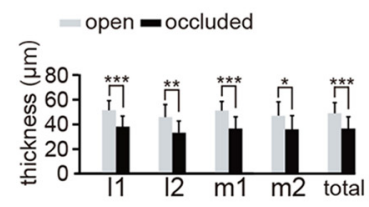

K

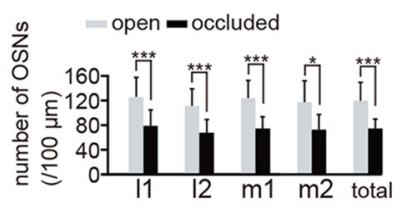

$\mathbf{L}$

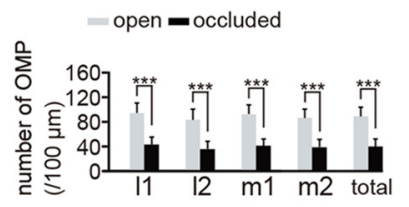


These observations indicate that incomplete OSN regeneration after sensory deprivation is applicable to the entire OE.

Newly generated OSNs extend axons that project through the cribriform plate to the surface of the $\mathrm{OB}$ and form excitatory synapses on the dendrites of $\mathrm{OB}$ projection neurons within the glomerular structure. Mature OSNs express OMP throughout their axons, including the axon terminals within the glomeruli (Mori and Sakano, 2011). To examine the effect of sensory deprivation on the axonal projections to the glomeruli of newly generated OSNs, we measured the OMP-stained area within individual glomeruli of the OBs on the open and occluded sides $3,7,14$, and $28 \mathrm{~d}$ after unilateral nostril occlusion. The axonal target glomeruli were selected from the ventromedial $\mathrm{OB}$ because the medial part of the $\mathrm{OE}$ that we examined for regeneration, including the nasal septum, projects to the medial OB (Fig. 4A, left, square outline).

Representative images of the ventromedial OB $28 \mathrm{~d}$ after saline administration (control) are shown in Figure $4 A$, middle. Representative histograms depicting the percentage of the area that was OMP-positive within individual glomeruli (immunostained axon terminals within the circled regions of the $\mathrm{OB}$ ) are presented in Figure 4A, right. The OMP-positive areas within individual glomeruli for both right and left OBs were $68.0 \%$ and $70.0 \%$, respectively. Using the same method, we calculated the

$\leftarrow$

Figure 3. Sensory deprivation inhibits complete replacement of newly generated OSNs after methimazole-induced injury. $\boldsymbol{A}$, Time course of the experimental design. Methimazole administration (intraperitoneal, i. ..) and unilateral nostril occlusion (unilateral n.o.) were performed at day 0 (d 0) and fixation (fix.) was conducted on days 3 (d3), 7 (d7), 14 (d14), and 28 (d28). (B) Photomicrographs of representative coronal sections through the nasal septum on days $3,7,14$, and 28 after methimazole-induced injury and unilateral nostril occlusion (injury + n.o.). Top, Lower magnification images; bottom, higher magnification of the portion of the $\mathrm{OE}$ depicted in top photographs indicated by the square. Left side of the image corresponds to the open side and the right side to the occluded side. Scale bars, $100 \mu \mathrm{m}$ at low magnification, $20 \mu \mathrm{m}$ at higher magnification. $\boldsymbol{C}-\boldsymbol{E}$, Thickness of the $\mathrm{OE}(\boldsymbol{C})$, number of olfactory sensory neurons $0 \mathrm{SN}$ s (D), and number of supporting cells $(\boldsymbol{E})$ on days 3, 7, 14, and 28 after methimazole-induced injury and unilateral nostril occlusion (injury + n.o.) and on days 14 and 28 after methimazoleinduced injury only (injury only). On days 14 and 28 after injury $+n .0$, the 0 E thickness and number of OSNs in the occluded side are reduced significantly compared with those in the open side $\left({ }^{*} p<0.05 ;{ }^{* * *} p<0.001\right.$; n.s., not significant; Mann-Whitney test). 0 n days 14 and 28 after injury $+n .0$, the thickness of the $O E$ and the number of $O S N s$ in the $O E$ are restored to those levels on the same days after methimazole-induced injury only (n.s., not significant; Mann-Whitney test). $\boldsymbol{F}$, Photomicrographs of representative coronal sections stained with anti-0MP antibody through the nasal septum in the open (left) and the occluded side (right) on days 3, 7, 14, and 28 after methimazole-induced injury and unilateral nostril occlusion (injury + n.o.). Scale bar, $20 \mu \mathrm{m}$. G, Number of OMP-positive cells on days 3, 7, 14, and 28 after methimazole-induced injury and unilateral nostril occlusion (injury + n.o.) and on days 14 and 28 after methimazole-induced injury (injury only). On days 14 and 28 after injury + n.o., the number of OMP-positive cells on the occluded side is significantly reduced compared with that on the open side $\left({ }^{* * *} p<0.001\right.$; Mann-Whitney test). On days 14 and 28 after injury $+n .0$, the number of OMP-positive cells is restored to those levels observed after methimazoleinduced injury only at the corresponding periods (n.S., not significant; Mann-Whitney test). $\boldsymbol{H}$, Immunohistological staining of the anti-neutrophil antibody in the $\mathrm{OE}$ (right) and bone marrow (left) on day 28 after methimazole-induced injury and unilateral nostril occlusion for both open and occluded sides. The $\mathrm{OE}$ is not stained with anti-neutrophil antibody, whereas the bone marrow as a positive control tissue is stained. Scale bars, $20 \mu \mathrm{m}$. $I$, Photomicrographs of representative coronal sections of the $0 \mathrm{E}$ on day 28 after methimazole-induced injury and unilateral nostril occlusion (injury + n.o.). Left, Lower magnification; right, higher magnification images of the areas indicated by the squares in the left image. Left and right sides of the lower magnification image correspond to the open and occluded sides, respectively. Scale bars, 200 $\mu \mathrm{m}$ at low magnification, $20 \mu \mathrm{m}$ at higher magnification. $J-L$, Thickness of the $0 \mathrm{E}(\boldsymbol{J})$, number of OSNs $(\boldsymbol{K})$, and number of OMP-positive cells $(\boldsymbol{L})$ obtained in each area $(11, \mathrm{~L}, \mathrm{m1}$, and $\mathrm{m} 2)$ on day 28 after methimazole-induced injury and unilateral nostril occlusion (injury $+n .0$.). The $\mathrm{OE}$ is thinner and the number of OSNs and OMP-positive cells are significantly fewer on the occluded side in all subareas compared with those on the open side $\left({ }^{*} p<0.05\right.$; ${ }^{* *} p<0.01$; ${ }^{* * *} p<0.001$; Mann-Whitney test). percent of the area that was OMP-positive within individual glomeruli $3,7,14$, and $28 \mathrm{~d}$ after unilateral nostril occlusion (Fig. $4 B, C)$. At $3 \mathrm{~d}$ after the injury, despite the absence of OSNs in the $\mathrm{OE}$, glomeruli in the OB showed robust OMP-staining due to the OMP-expression of the remaining degenerating olfactory axons. However, the OMP-positive area within the individual glomeruli gradually decreased on days 7 and 14 compared with that on day 3 (Fig. $4 B, C$ ), presumably due to the clearance of the degenerating olfactory axons. Up to day 7 , there were no significant differences in the percentage of OMP-positive areas between the open and occluded sides (day 3, $p=0.3$, day 7, $p=0.56$; MannWhitney test; Fig. 4C). On day 14, a more prominent reduction in the percent of the OMP-immunostained area was observed on the occluded side ( $p<0.001$, Mann-Whitney test; Fig. $4 C)$. However, on day 28, the percentage of the OMP-immunostained area on the open side was increased compared with that on day 14 and was similar to that observed $28 \mathrm{~d}$ after methimazole-induced injury without nostril occlusion ( $p=0.37$, Man-Whitney test; Fig. $4 C$ ). In contrast, the percentage of the OMP-immunostained area on the occluded side was markedly less than that on the open side on day 28 ( $p<0.05$, Mann-Whitney test; Fig. $4 C$ ), suggesting that sensory deprivation resulted in the projection of axons from fewer newly generated OSNs.

To determine whether this incomplete regeneration observed in the ventromedial $\mathrm{OB}$ occurred in other quadrants of the $\mathrm{OB}$, we measured the OMP-stained area within glomeruli of the three remaining quadrants. Figure $4 D$ shows a schematic of a coronal section through the $\mathrm{OB}$ displaying the four quadrants: ventromedial (v-m), ventrolateral (v-l), dorsomedial (d-m), and dorsolateral (d-l). The area of the OMP-stained OB glomeruli in the three remaining quadrants of the occluded side was significantly less than that of the open side (d-1, $p<0.001 ; \mathrm{d}-\mathrm{m}, p<0.001 ; \mathrm{v}-\mathrm{l}, p<$ 0.001; total, $p<0.001$, Mann-Whitney test; Fig. $4 E, F)$. These results are consistent with the histological changes observed throughout the entire $\mathrm{OE}$ and support the idea that sensorydeprivation-induced incomplete regeneration of new neurons after injury occurs broadly throughout the OB (Fig. 3).

To determine whether sensory deprivation affects functional incorporation of new OSNs into olfactory circuits, we performed intrinsic imaging of the glomerular responses to odorant stimulation at the dorsal surface of the $\mathrm{OB}$ (Fig. $5 \mathrm{~A}$ ). The glomerular responses were evaluated $28 \mathrm{~d}$ after unilateral nostril occlusion, with the silicone tube removed $12 \mathrm{~h}$ before the imaging for the reopened side. We stimulated the $\mathrm{OE}$ on both the right and left sides with odorants and compared the glomerular responses between reopened and open sides (Fig. 5B). Representative examples of intrinsic imaging in three mice are shown in Figure $5 B$. We observed that the mean responsive area for the TMT and 2-MBA stimulation on the open side was significantly greater than that on the reopened side ( $n=9$ mice; TMT, $p<0.05 ; 2-\mathrm{MBA}, p<$ 0.05; Mann-Whitney test, Fig. $5 B, C$ ). The mean intensities for the TMT- and 2-MBA-induced responses on the open side were significantly greater than those on the reopened side (TMT, $p<$ 0.01; 2-MBA, $p<0.05$; Steel-Dwass test; Fig. $5 B, D$ ). The mean intensities of the air-induced responses did not differ significantly between the reopened and open sides ( $p=0.89$, Steel-Dwass test; Fig. $5 B, D$ ), whereas the mean intensities of the TMT- and 2-MBAinduced responses for both reopened and open sides were significantly greater than those of the air-induced responses $(p<0.01$ for all comparisons; Steel-Dwass test; Fig. $5 B, D$ ). These results suggest that the gradual regeneration of the OE by the addition of new OSNs and their axonal projections to the glomeruli parallels the increase in the glomerular responses to odorants. 
A

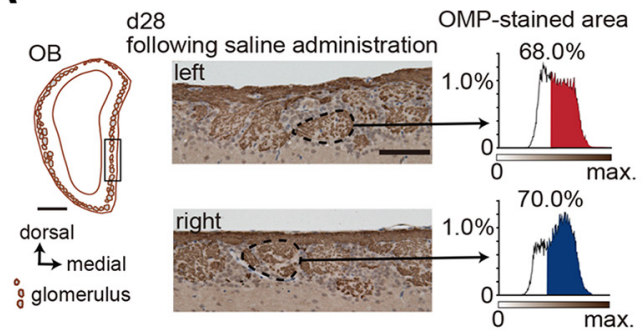

C

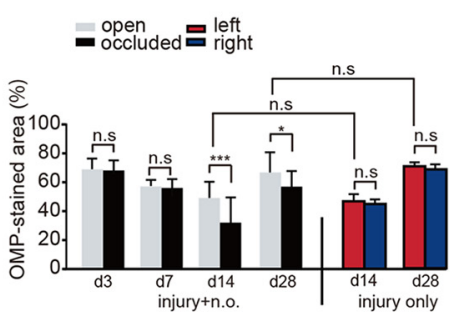

B

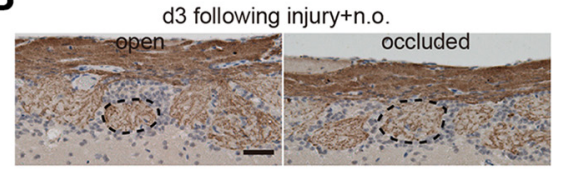

d14 following injury+n.o.

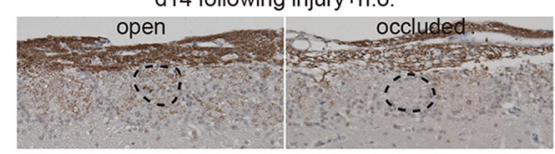

D

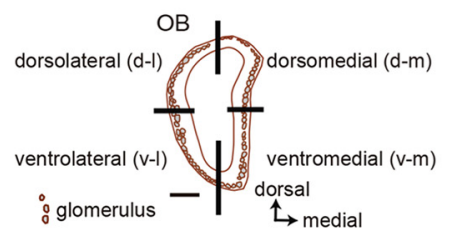

$\mathbf{F}$

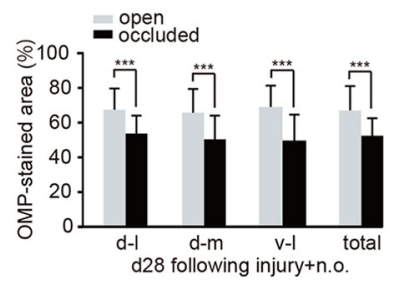

E

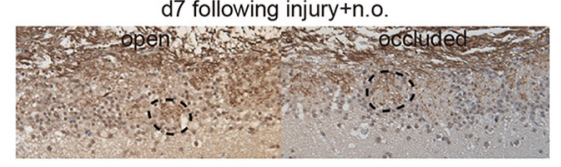

d28 following injury $+n .0$
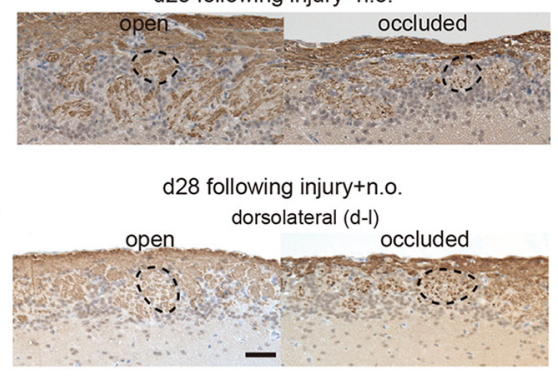

dorsomedial (d-m)

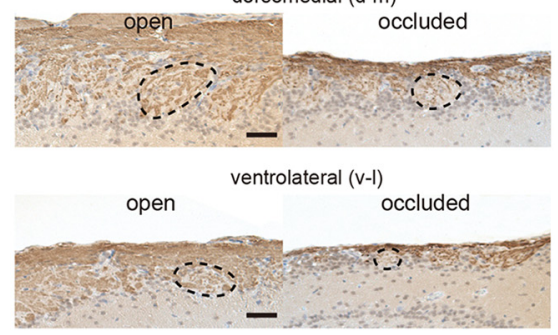

Figure 4. Sensory deprivation results in the projection of axons from fewer newly generated OSNs. A, Analysis area of the OB. Left, coronal section of the $O B$. Square shows seven analyzed glomeruli in the $O B$. Scale bar, $500 \mu \mathrm{m}$. Middle, representative images of the left and right $O B$ captured at day 28 after saline administration. Right, Intensity histograms of the OMPimmunostained area within glomeruli on both left and right sides. OMP-immunostained areas are shown in red for the left side and in blue for the right side of the $\mathrm{OB}$. $\boldsymbol{B}$, Representative coronal sections stained with anti-OMP antibody in the open (left) and the occluded (right) sides at days 3 (d3), 7 (d7), 14 (d14), and 28 (d28) after methimazole-induced injury and unilateral nostril occlusion. Each circled area corresponds to a glomerulus. Scale bar, $50 \mu \mathrm{m}$. C, Summary for the ratio of areas immunostained and unstained with OMP. The percentage of OMP-stained areas on days 3, 7, 14, and 28 after methimazole-induced injury and unilateral nostril occlusion (injury + n.o.) and on days 14 and 28 after methimazole-induced injury (injury only). OMP-stained area on the occluded side is significantly reduced compared with that on the open side on days 14 and 28 after methimazole-induced injury with unilateral nostril occlusion $\left({ }^{*} p<0.05,{ }^{* * *} p<0.001\right.$; Mann-Whitney test). However, the $0 \mathrm{MP}$-immunostained area does not differ for these two conditions on days 14 and 28 (Mann-Whitney test). D, Schematic showing the quadrants of a coronal section through the $\mathrm{OB}$ (dorsolateral, d-l; dorsomedial, d-m; ventrolateral, v-l; and ventromedial, v-m). Scale bar, $500 \mu \mathrm{m} . \boldsymbol{E}$, Representative coronal sections of each $\mathrm{OB}$ quadrant stained with anti-OMP antibody on the open (left) and the occluded (right) sides on day 28 (d28) after methimazole-induced injury and unilateral nostril occlusion (injury + n.o.). Each circled area corresponds to a glomerulus. Top, Dorsolateral quadrant (d-l); middle, dorsomedial quadrant (d-m); bottom, ventrolateral quadrant (v-I). Scale bar, $50 \mu \mathrm{m}$. F, Summary for the ratio of areas immunostained and unstained with OMP in each quadrant of the $0 B$. The percent of the OMP-stained areas in each quadrant of the occluded side is significantly bottom than that of the open side ${ }^{* * *} p<$ 0.001; Mann-Whitney test).

Technical limitations rendered the ventral OB inaccessible using this imaging method, so it remained unclear whether the weak responses observed on the reopened side compared with those on the open side would also be observed in the ventral $\mathrm{OB}$. To address this issue, we examined the expression of c-fos (a neural activity marker) induced by odor in the dorsal and ventral $\mathrm{OB}$ and compared the number of $\mathrm{c}$-fos-positive cells in the open and reopened sides. If relatively weak afferent inputs

to the $\mathrm{OB}$ were observed in the reopened side, fewer c-fos-positive cells would be expected in the reopened $\mathrm{OB}$ compared with the open $\mathrm{OB}$.

c-fos expression was evaluated $28 \mathrm{~d}$ after unilateral nostril occlusion, with the silicone tube removed $12 \mathrm{~h}$ before the odor stimulation for the reopened side. Aldehyde, lactone, and ester categories were selected as stimulus odorants for activating the dorsal and ventral $\mathrm{OB}$ based on our previous studies (Kikuta et al., 2008, 2010). Representative coronal sections of the OB (left, reopened side; right, open side) stained with an anti-c-fos antibody are shown in Figure 5E. Stimulus odorants induced c-fos expression within the glomerular and granule cell layers broadly throughout the dorsal and ventral OBs of the reopened and open sides (Fig. $5 E)$. We focused on the c-fos expression within the glomerular layer because the increase in c-fos expression within the glomerular layer is glomerulus region specific (Jin et al., 1996). The c-fospositive cells within the glomerular layer were plotted on sections from the three $\mathrm{OB}$ regions (caudal, middle, and rostral; Fig. $5 F$ ). In each region from the dorsal and ventral $\mathrm{OB}$, there were significantly fewer odor-induced c-fos-positive cells on the reopened side than on the open side ( $n=5$ mice; dorsal, $p<0.001$; ventral, $p<0.05$; total, $p<0.001 ;$ Mann-Whitney test; Fig. $5 G$ ).

The silicone tube may produce hypertrophy of the nasal mucosa through continuous topical stimulation, resulting in decreased nasal airflow in the reopened side. To determine whether the decreased signals and fewer c-fos-positive cells in the $\mathrm{OB}$ in the reopened side compared with those in the open side resulted from decreased neural activity or decreased nasal airflow, we compared nasal airflow between the reopened and open sides. Figure $5 \mathrm{H}$ illustrates representative frequency and airflow traces as well as the averaged airflow. We did not observe significant differences in the mean frequency and amplitude for the airflow between the reopened and the open sides $(n=10$ mice in each group; mean frequency, $p=0.50$; mean amplitude, $p=0.21$; Mann-Whitney test; Fig. $5 I, J)$. These results indicate that the decreased glomerular responses to odor stimulation and fewer c-fos-positive cells in the $\mathrm{OB}$ are due to incomplete recruitment of functional OSNs in the connections between the $\mathrm{OE}$ and $\mathrm{OB}$, suggesting that sensory deprivation during the $28 \mathrm{~d}$ period results in a decreased degree of functional incorporation of new neurons into olfactory circuits. 
A

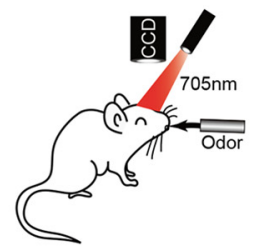

C

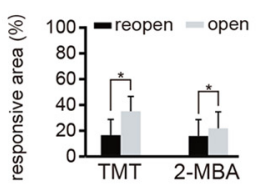

D

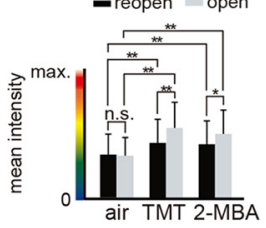

B
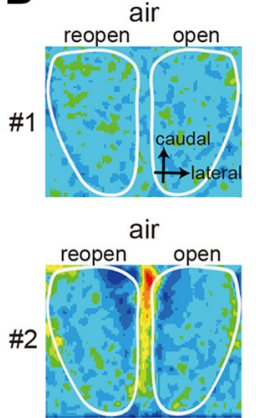

air

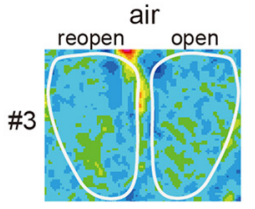

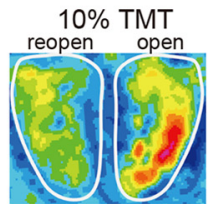

$10 \%$ TMT

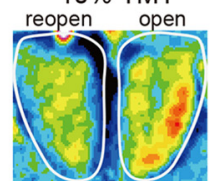

$10 \%$ TMT

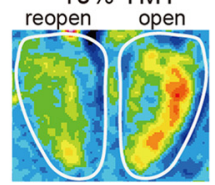

$10 \% 2-\mathrm{MBA}$

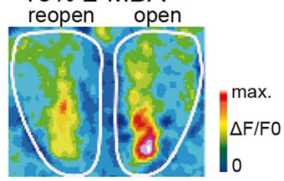

$10 \% 2-\mathrm{MBA}$

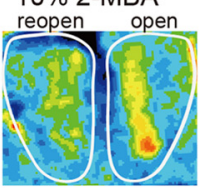

$10 \% 2-\mathrm{MBA}$

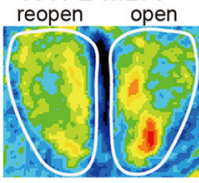

E
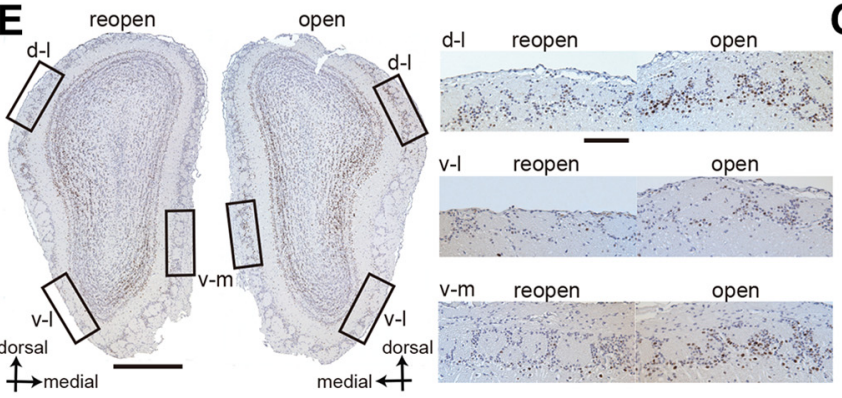

G

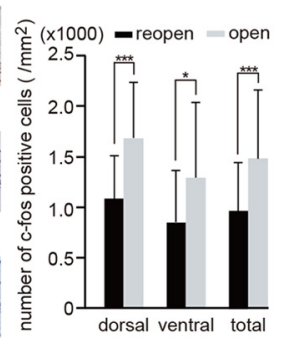

$\mathbf{F}$
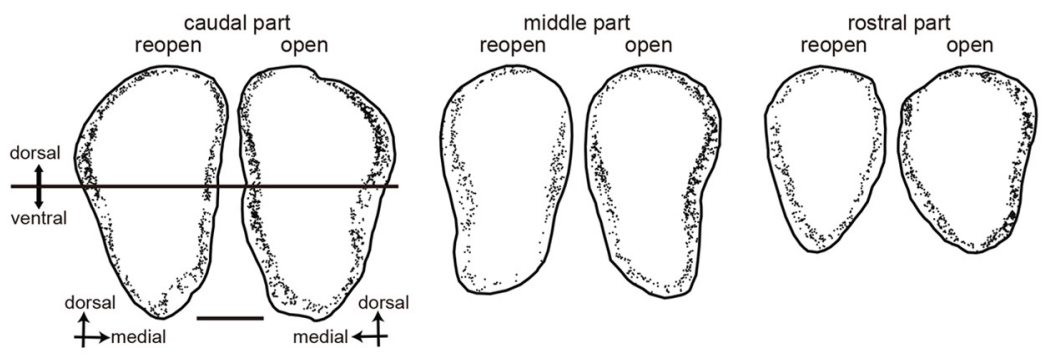

H
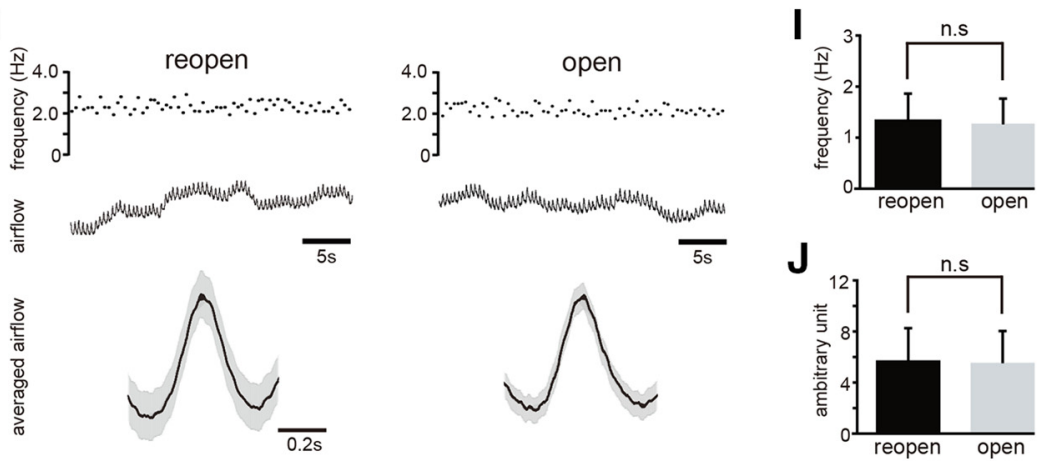

Figure 5. Sensory deprivation disrupts functional incorporation of newly generated OSNs after injury. $\boldsymbol{A}$, Schematic diagram of in vivo intrinsic imaging. Intrinsic neural activity after stimulation with odors was recorded through a $C C D$ camera. $\boldsymbol{B}$, Representative functional images showing the dorsal view of the $0 B$ in three mice (\#1, \#2, and \#3). Administration of TMT and 2-MBA was used for activating the dorsal zone of the $O B$. A silicone tube was inserted and remained in the left nostril for $28 \mathrm{~d}$; the tube was removed $12 \mathrm{~h}$ before imaging. Left, Reopened side; right, open side. The intensity of the imaging signals are shown as pseudocolors. $C$, Percentage of the area responsive to stimulation with the odorants TMT and 2-MBA in the reopened and open sides shows that the responsive area of the reopened side is significantly reduced ( ${ }^{*} p<0.05$; Wilcoxon $t$ test). D, Mean intensity of imaging signals after stimulation with TMT and 2-MBA in the reopened and the open sides. The mean intensities of the signals induced by both TMT and 2-MBA are significantly greater than those induced by air $\left({ }^{* *} p<0.01\right.$; Steel-Dwass test), whereas TMT- and 2-MBA-induced responses on the reopened side are significantly reduced compared with those on the open side $\left({ }^{*} p<0.05 ;{ }^{* *} p<0.01\right.$; Steel-Dwass test). $\boldsymbol{E}$, 0dor-induced $c$-fos expression in the OB. Representative OB coronal sections stained

\section{Sensory deprivation downregulates proliferation of OSNs}

The sensory-deprivation-induced incomplete replacement of OSNs may result from decreased OSN proliferation. To examine the extent of the OSN proliferation, we observed Ki67-positive cells (a cell marker of proliferation) in the $\mathrm{OE}$ on days $3,7,14$, and 28 after injury using three different conditions (nostril occlusion only, methimazole-induced injury only, and both of these combined; Fig. 6). In the group receiving unilateral nostril occlusion only, sensory deprivation during the first $7 \mathrm{~d}$ did not induce significant changes in the number of Ki67-positive cells on either the occluded or open side, whereas, after $14 \mathrm{~d}$, there were significantly fewer Ki67-positive cells on the occluded side compared with those on the open side (day $3, p=0.86$; day $7, p=0.79$; day 14 , $p<0.01$; day 28, $p<0.01$; Mann-Whitney test; Fig. $6 A$ ).

After the methimazole-induced injury, the number of Ki67-positive cells on both sides increased greatly on day 3 , but their numbers gradually decreased during the later periods (Fig. 6B). We observed no significant differences in the number of Ki67-positive cells between left and right sides at any time after methimazoleinduced injury (day $3, p=0.57$, day $7, p=$

\section{$\leftarrow$}

with anti-c-fos antibody on day 28 after methimazole-induced injury and unilateral nostril occlusion (left, reopened side; right, open side). Right, Higher magnification images captured from the areas indicated by the squares on the left panel (dorsolateral, d-l; ventrolateral, v-l; ventromedial, v-m). Lactones, esters, and aldehydes were selected as stimulus odorants to induce $c$-fos immunoreactivity in the $0 B$ neurons. Scale bars, $500 \mu \mathrm{m}$ at low magnification, $100 \mu \mathrm{m}$ at higher magnification. $F$, Labeling of c-fos-positive cells within the glomerular layer in the caudal, middle, and rostral regions of the $\mathrm{OB}$. The c-fos positive cells were plotted with a computer-assisted mapping system. Reactive cells are scattered throughout the dorsal and ventral regions of the $O B$. Caudal region of the $O B$ corresponds to the image shown in $E$. Top half of the $0 B$, dorsal region; bottom half of the $O B$, ventral region. Scale bar, 500 $\mu \mathrm{m} . \mathbf{G}$, Comparison of the number of c-fos-positive cells between the reopened and open sides in the dorsal and ventral regions of the $O B$. The number of $c-$ fos-positive cells (per $\mathrm{mm}^{2}$ ) in the dorsal and ventral $O B$ of the open side was significantly greater than that on the reopened side ${ }^{*} p<0.05$, ${ }^{* * *} p<0.001$; Mann-Whitney test). $\boldsymbol{H}$, Nasal airflow in the reopened (black) and the open (gray) sides. Top traces, Frequency of respirations during $30 \mathrm{~s}$. Middle traces, Nasal airflow. Bottom traces, Averaged airflows during $30 \mathrm{~s}$. Black line indicates mean airflow; gray range, mean \pm SEM. $I$, Frequency of the nasal airflow ( $n=10$ mice) in the reopened and open sides. Significant differences are not detected (n.S., not significant; Wilcoxon $t$ test). $J$, Amplitude of the nasal airflow $(n=10$ mice) in the reopened and open sides. Significant differences are not detected (n.s., not significant; Wilcoxon $t$ test). 
A

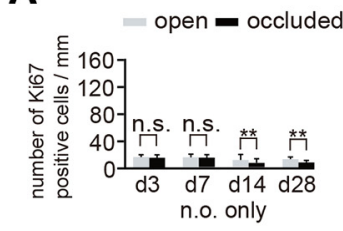

B

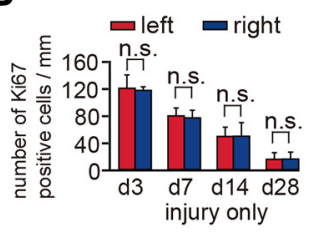

D

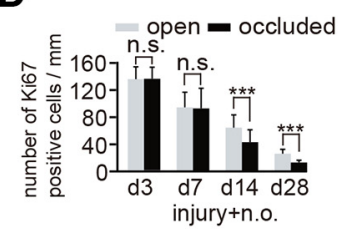

C

d3 following injury + n.o.

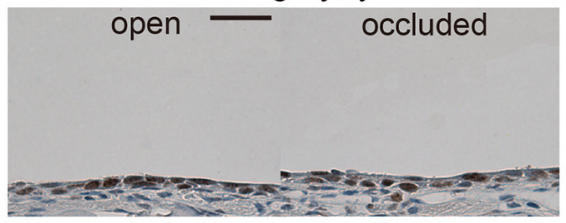

d14 following injury + n.o.

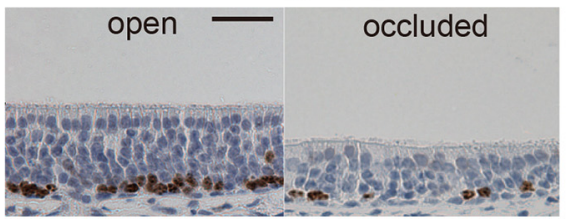

d7 following injury + n.o.

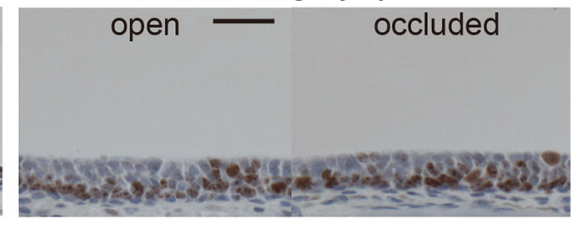

d28 following injury + n.o.

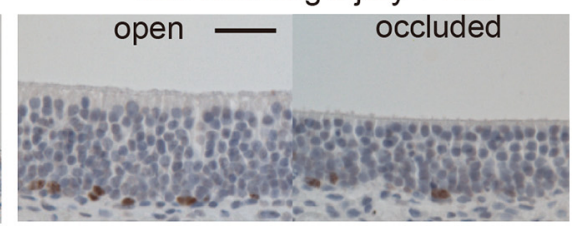

Figure 6. Ki67-positive cells on the occluded side decrease 14 and 28 d after injury. $A$, The number of Ki67-positive cells through the nasal septum in the open and occluded sides on days 3 (d3), 7 (d7), 14 (d14), and 28 (d28) after unilateral nostril occlusion. On days 14 and 28 after unilateral nostril occlusion, the number of Ki-67-positive cells on the occluded side is significantly decreased compared with that on the open side ( ${ }^{* *} p<0.01$; Mann-Whitney test). $\boldsymbol{B}$, Number of Ki67-positive cells through the nasal septum at $3,7,14$, and $28 \mathrm{~d}$ of sensory deprivation. The number of Ki67-positive cells peaks at day 3 after injury and then gradually decreases. Methimazole administration does not induce significant changes in the number of Ki67-positive cells between the left and right sides at any time (n.S., not significant; Mann-Whitney test). C, Coronal sections stained with anti-Ki67 antibody in the open and occluded sides on days 3, 7, 14, and 28 after methimazole-induced injury and unilateral nostril occlusion. Scale bar, 20 $\mu \mathrm{m}$. D, Number of Ki67-positive cells through the nasal septum in the open and occluded sides at days 3, 7, 14, and 28 after methimazole-induced injury and unilateral nostril occlusion. On days 14 and 28 after methimazole-induced injury and unilateral nostril occlusion, the total number of Ki67-positive cells is significantly decreased on the occluded side compared with that on the open side $\left({ }^{* * *} p<0.001\right.$; Mann-Whitney test).

0.57 , day $14, p=0.95$, day $28, p=0.86$; Mann-Whitney test; Fig. $6 B)$. Figure $6 C$ shows representative images of the nasal septum stained with the anti-Ki67 antibody on the open and occluded sides after injury. The number of Ki67-positive cells on both open and occluded sides peaked $3 \mathrm{~d}$ after methimazole-induced injury combined with unilateral nostril occlusion and then gradually decreased (Fig. 6D). However, this decrease was significantly more marked on the occluded side than on the open side on days 14 and 28 (day $3, p=0.96$, day $7, \mathrm{p} 0.89$, day $14, p<0.001$, day 28 , $p<0.001$; Mann-Whitney test; Fig. $6 D$ ). These results indicate that sensory deprivation for $>14 \mathrm{~d}$ downregulates OSN proliferation regardless of injury and potentially impedes the replacement of newly generated OSNs after injury.

\section{Sensory deprivation enhances apoptotic cell death in immature neurons}

Another possible explanation for the sensory-deprivationinduced incomplete replacement of new OSNs is that sensory deprivation may increase death in the new OSNs. To examine this possibility, we determined the expression of active caspase- 3 in the $\mathrm{OE}$ on days 7,14 , and 28 under three different conditions (nostril occlusion only, methimazole-induced injury only, and both of these combined; Fig. 7) with an antibody specific for the active (cleaved) form of caspase-3, a marker of apoptotic cell death that functions in most downstream caspase-activation cascades (Olney et al., 2002; Yuan et al., 2003). After unilateral nostril occlusion, caspase-3-positive cells were rarely detected and no significant differences were observed between the occluded and open sides (day $7, p=0.93$, day $14, p=0.67$, day 28, $p=0.75$; Mann-Whitney test; Fig. $7 A$ ), indicating that susceptibility to apoptosis for mature neurons is low and independent of sensory deprivation periods. After methimazole-induced injury, no significant differences were observed at any time or for either side (day 7, $p=0.45$, day 14 , $p=0.09$, day 28, $p=0.47$; Mann-Whitney test; Fig. $7 B$ ). A significant number of caspase-3-positive cells were observed in mice with methimazole injury combined with unilateral nostril occlusion and representative images of the $\mathrm{OE}$ from both the open and occluded sides are shown for days 7, 14, and 28 after injury in Figure 7C. On day 7, activated caspase-3-positive cells were barely detected in the nasal septum of the OE for both the open and occluded sides ( $p=0.31$; Mann-Whitney test; Fig. $7 C, D)$. However, on days 14 and 28 , the number of activated caspase-3positive cells on the occluded side was significantly higher than that on the open side (day 14, $p<0.001$, day 28, $p<0.001$; Mann-Whitney test; Fig. 7D). The susceptibility to apoptosis of newly generated OSNs was greatest for the observed days on day 14 (day 7 vs day 14, $p<0.001$; day 14 vs day $28, p<0.001$; day 7 vs day 28 , $p<0.001$; Steel-Dwass test; Fig. 7D). These results indicate that the susceptibility to apoptosis after injury for newly generated OSNs varies across the maturation process.

To determine whether the enhanced apoptotic cells appearing on the occluded side on day 14 were immature or mature OSNs, we colabeled OSNs with the anti-caspase- 3 antibody and the antiOMP antibody (Fig. 7E). A majority of the caspase-3-positive cells (82 of 89 caspase-3-positive cells analyzed, $92.1 \%$, three mice, white arrowheads in Fig. $7 E$ ) were not colabeled with OMP, whereas the few remaining cells were colabeled with OMP (7 of 89 caspase-3-positive cells analyzed, 7.9\%, yellow arrowhead in Fig. 7E), indicating that nearly all the apoptotic cells were immature. Together, these results indicate that, during sensory deprivation, apoptotic cell death in immature OSNs is enhanced and that their susceptibility to cell death varies with their stage of maturation.

\section{Specific time window exists for sensory-input-dependent survival or cell death in new OSNs}

Granule cells newly generated in the OBs of adults have a critical period during their maturation for sensory-input-dependent survival or death (Yamaguchi and Mori, 2005). By analogy, we hypothesized that new OSNs would show enhanced susceptibility to apoptotic cell death when they became OMP-positive mature cells. Therefore, new OSNs may have a specific critical time window for sensory-input-dependent survival or cell death. To examine this possibility, we determined the effect of sensory deprivation on OSN regeneration in an early period $(0-7 \mathrm{~d}$ after injury; Fig. $8 A$, top) and a late period (7-14 d after injury; Fig. $8 A$, bottom). As shown above, sensory deprivation for $14 \mathrm{~d}$ was sufficient to observe incomplete regeneration of new neurons 
after methimazole-induced injury (Fig. 3) and OMP-positive neurons emerged 7-14 $\mathrm{d}$ after injury (Figs. 2, 3). The details of this next experiment are described in Figure $8 A$. Briefly, the mice in two experimental groups received unilateral nostril occlusions after administration of methimazole and were perfused with fixative $14 \mathrm{~d}$ after the methimazole-induced injury $(n=3$ mice per group; Fig. $8 A$ ). The timing for the unilateral nostril occlusion differed between the 2 groups such that 1 group of mice received the occlusion $0-7$ $\mathrm{d}$ after the methimazole-induced injury (Fig. 8A, top) and the other group received the occlusion 7-14 d after the injury (Fig. $8 A$, bottom). Representative coronal sections of the nasal septum for both groups are shown in Figure $8 B$. In the group subjected to sensory deprivation during days $0-7$, the thickness of the $\mathrm{OE}$, total number of OSNs, and the number of supporting cells did not differ between the open and occluded sides (thickness, $p=$ 0.57 ; number of OSNs, $p=0.89$; number of supporting cells, $p=0.53$; MannWhitney test; Fig. $8 C-E$ ). In contrast, sensory deprivation on days 7-14 caused a significant thinning of the $\mathrm{OE}$ with fewer OSNs (thickness, $p<0.001$; number of OSNs, $p<0.001$; number of supporting cells, $p=0.56$; Mann-Whitney test; Fig. $8 C-E)$. Representative images of the nasal septum stained with anti-OMP antibody are shown in Figure $8 F$. The number of OMP-positive cells for both the open and occluded sides did not differ during sensory deprivation $0-7 \mathrm{~d}$ after injury ( $p=$ 0.79; Mann-Whitney test; Fig. 8G). However, during sensory deprivation 7-14 d after the methimazole-induced injury, the number of OMP-positive cells was significantly lower on the occluded side than that on the open side $(p<0.001$; MannWhitney test; Fig. $8 G$ ). These results indicate that sensory input 7-14 d after injury plays a crucial role in the replacement process of newly generated OSNs.

To determine whether incomplete regeneration contributed to an increased susceptibility to apoptotic cell death during sensory deprivation 7-14 d after methimazole-induced injury, we compared the number of caspase-3-positive cells in mice with nostril occlusions starting $0-7 \mathrm{~d}$ after the injury with those starting 7-14 d after injury (Fig. 8H,I). The number of caspase-3-positive cells on the occluded side was significantly higher during the sensory deprivation 7-14 d after injury than that on the open side, whereas no significant difference was observed between the open and occluded
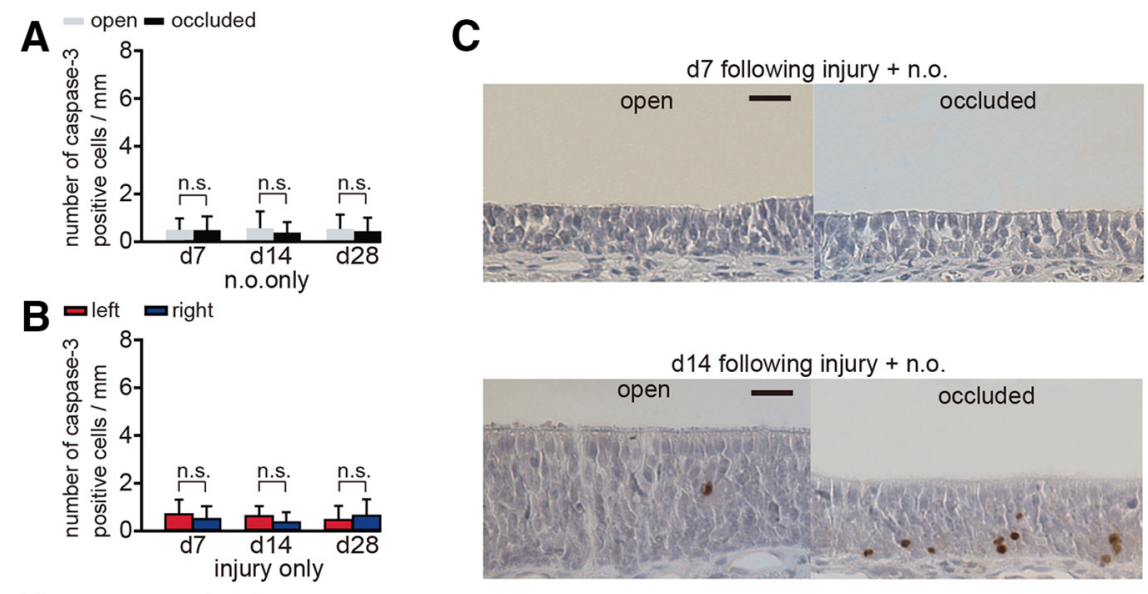

D

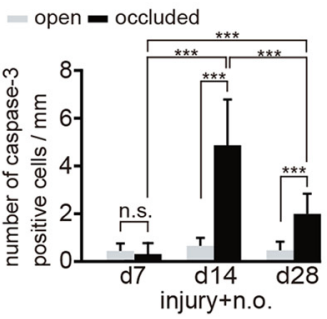

E
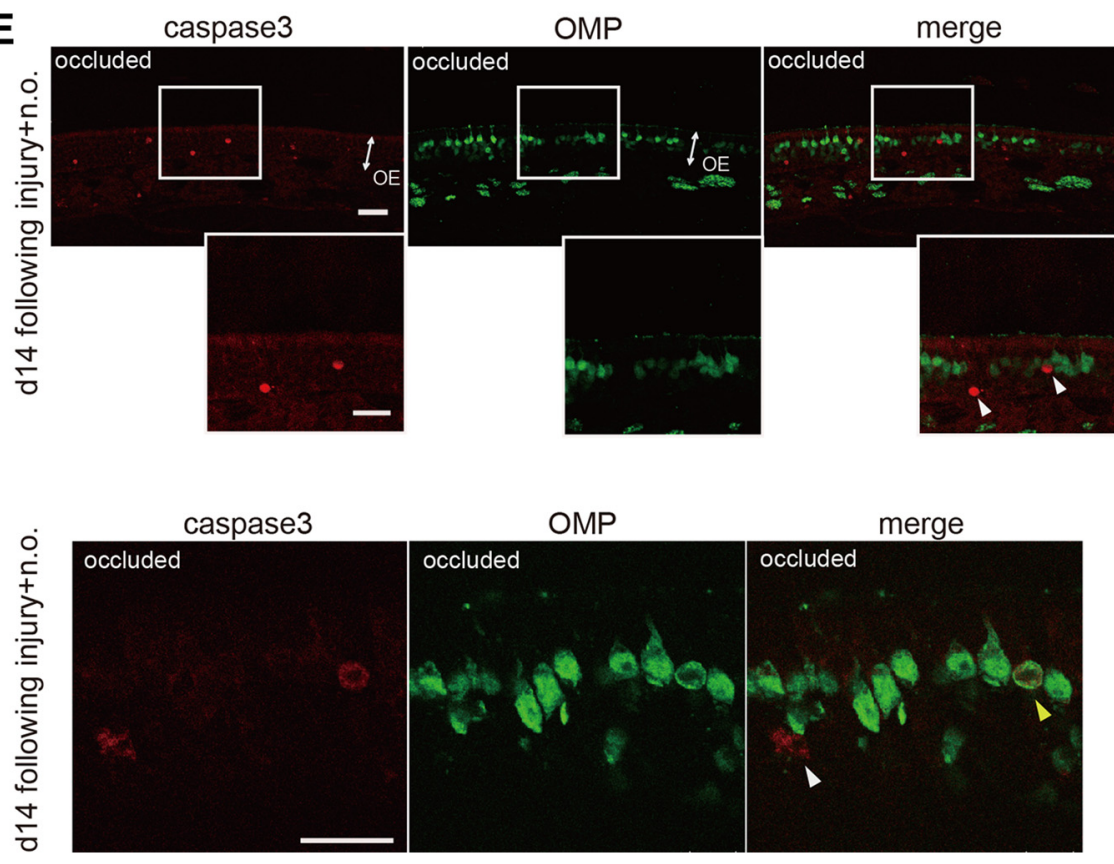

Figure 7. Caspase-3-activated immature cells increase 14 and $28 \mathrm{~d}$ after methimazole-induced injury combined with nostril occlusion. $\boldsymbol{A}$, Number of caspase-3-positive cells through the nasal septum on the open and occluded sides at days 7 (d7), 14 (d14), and 28 (d28) after unilateral nostril occlusion. Nostril occlusion does not induce a significant change in number of caspase-3activated cells between the open and occluded sides at any time point (n.S., not significant; Mann-Whitney test). $\boldsymbol{B}$, Number of caspase-3-positive cells through the nasal septum on days 7, 14, and 28 after injury. Methimazole administration does not induce a significant change in the number of caspase-3-activated cells between the left and right sides at any time (n.s., not significant; Mann-Whitney test). C, Coronal sections through the nasal septum stained with anti-caspase-3 antibody in the open and occluded sides at days 7, 14, and 28 after methimazole-induced injury with unilateral nostril occlusion. Scale bar, $20 \mu \mathrm{m}$. D, Number of caspase-3-positive cells through the nasal septum in the open and occluded sides on days 7, 14, and 28 after methimazole-induced injury with unilateral nostril occlusion. On days 14 and 28, the total number of caspase-3-positive cells on the occluded side is significantly higher than that on the open side ( ${ }^{* *} p<0.001$; Mann-Whitney test). $\boldsymbol{E}$, Coronal sections through the nasal septum stained with anti-caspase-3 (red) antibody and anti-0MP (green) antibody from the occluded side $14 \mathrm{~d}$ after methimazole-induced injury combined with unilateral nostril occlusion. Two representative images of the OE are shown in the top and bottom. The middle row of images shows a higher magnification of the $0 E$ captured from the boxed regions shown in the top row of images. White arrowheads indicate caspase-3-positive apoptotic cells that are not costained with an anti-0MP antibody, whereas the yellow arrowhead indicates a caspase-3-positive apoptotic cell costained with the anti-0MP antibody. A majority of caspase-3positive cells were not costained with the anti-0MP antibody. Scale bar, $20 \mu \mathrm{m}$. 
A

n.o. (d0-7)

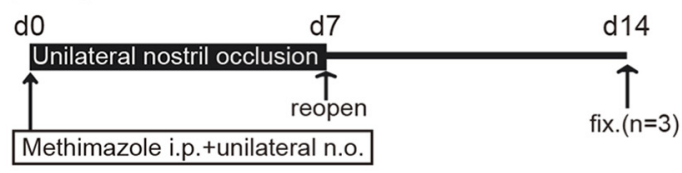

n.o. $(d 7-14)$

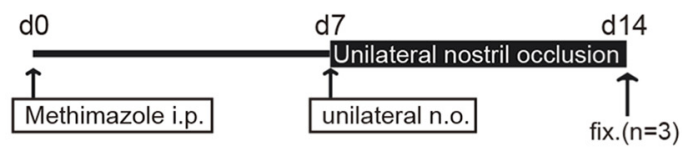

B

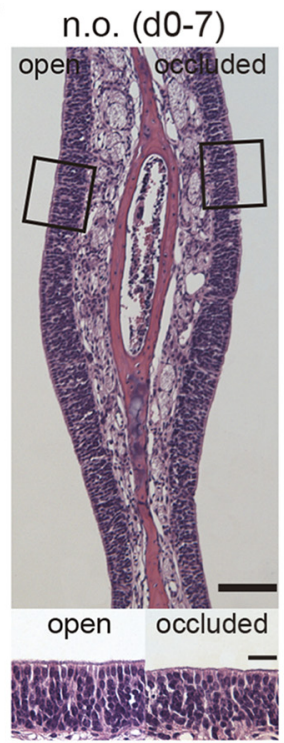

$\mathbf{F}$

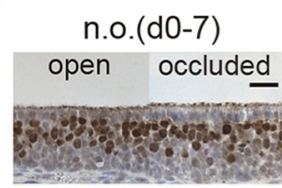

n.O. $(d 7-14)$

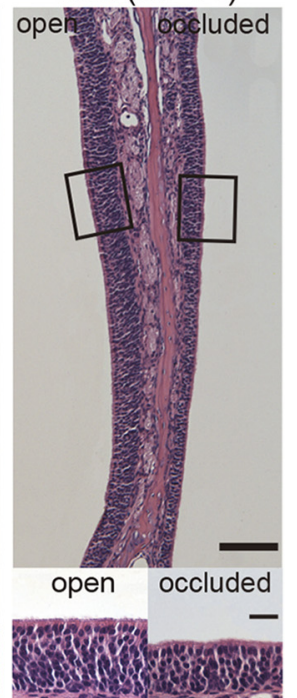

n.o.(d7-14)

open occluded

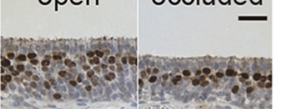

H
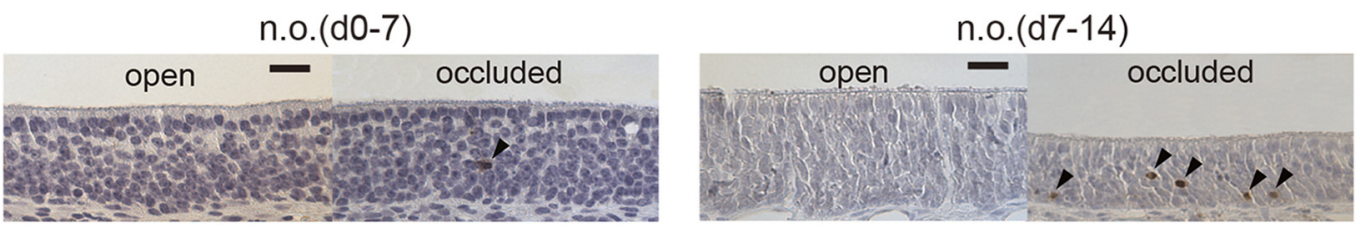

J
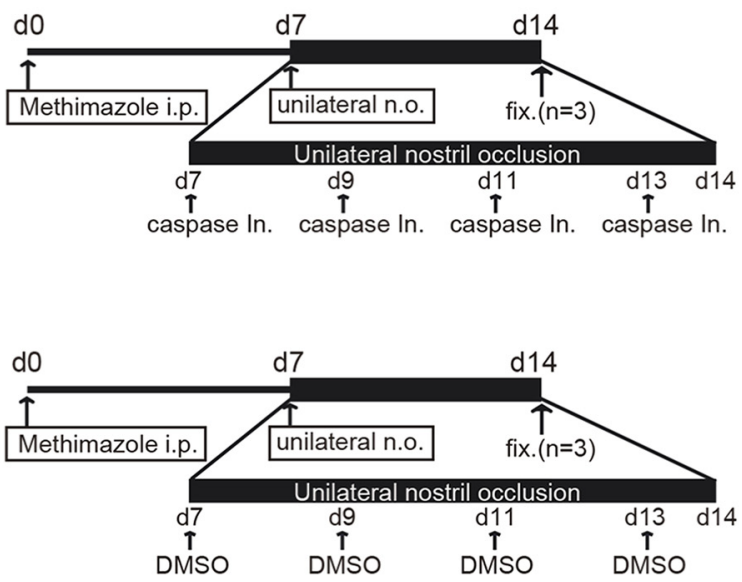

K

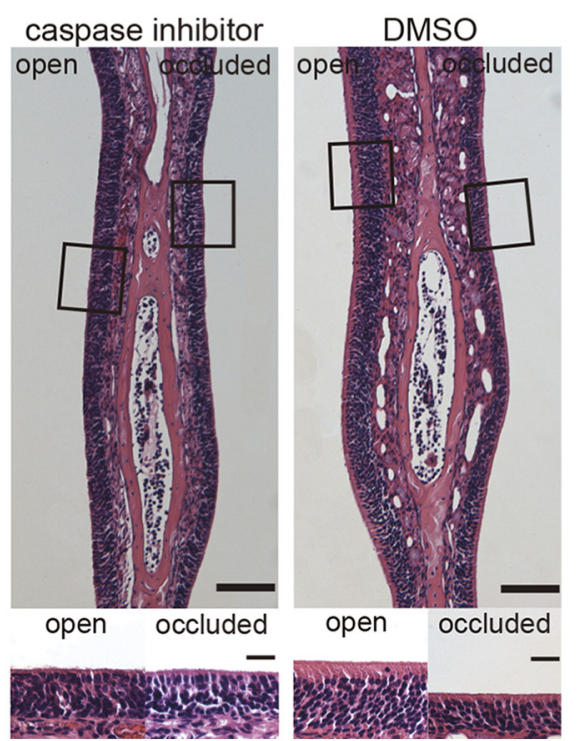

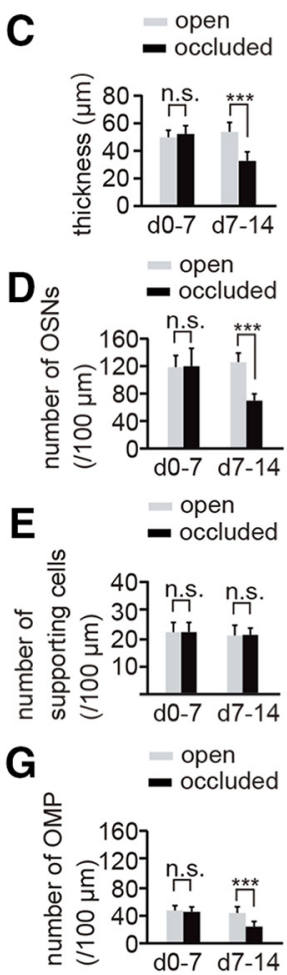

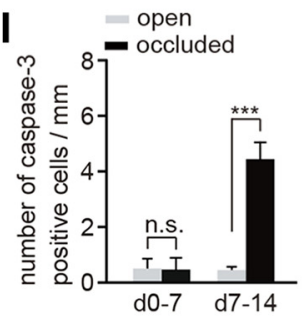

$\mathbf{L}$

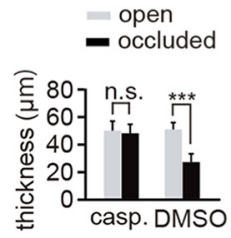

M

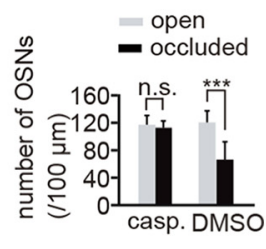

N

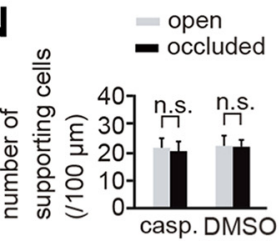

Figure 8. Susceptibility to apoptosis in newly generated 0SNs is enhanced 7-14 after injury and unilateral nostril occlusion. $A$, Mice in two experimental groups received unilateral nostril occlusions (n.o.) at different times after methimazole-induced injury. Top, Sensory deprivation $0-7$ d, n.o. (d0 -7); bottom, sensory deprivation 7-14, n.o. (d7-14). Mice in the n.0. d 0 -7 group received both methimazole administration and unilateral nostril occlusion on day 0 ; however, the nostril occlusion was removed on day 7 (reopen). Mice in the n.0. $d 7-14$ group received methimazole administration on day 0 and unilateral nostril occlusion on day 7. Mice in both groups were perfused with fixative (fixed) on day 14 after the methimazole-induced injury. $\boldsymbol{B}$, Photomicrographs of representative coronal sections of the olfactory nasal septum in the two groups. Higher magnification views of the $\mathrm{OE}$ captured from the area depicted by the square are illustrated in the bottom photomicrographs. Scale bars, $100 \mu \mathrm{m}$ (lower magnification) and $20 \mu \mathrm{m}$ (higher magnification). $\boldsymbol{C}-\boldsymbol{E}$, Thickness of the $0 \mathrm{E}(\boldsymbol{C})$, number of $0 \mathrm{SNs}(\boldsymbol{D})$, and number of supporting cells $(\boldsymbol{E})$ in both the n.o. $\mathrm{d} 0-7$ and n.o. d 7-14 groups. $\boldsymbol{F}$, Representative coronal sections of the olfactory nasal septum stained with anti-0MP antibody (Figure legend continues.) 
sides $0-7 \mathrm{~d}$ after injury $(0-7 \mathrm{~d}, p=0.68 ; 7-14 \mathrm{~d}, p<0.001$; Mann-Whitney test; Fig. $8 I$ ). These results indicate that the susceptibility to apoptosis in newly generated OSNs is enhanced during sensory deprivation 7 and $14 \mathrm{~d}$ after methimazoleinduced injury and that newly generated OSNs may have a specific time window for sensory-dependent survival or death.

To determine whether the survival of new neurons 7-14 d after an injury contributes to homeostatic tissue regulation, we administered a caspase inhibitor once every other day during the 7-14 d after methimazole-induced injury (4 times total; Fig. 8J, top). As a control, mice in a second group received $10 \%$ DMSO intraperitoneally on the same schedule during the same period (Fig. 8J, bottom). Representative images of both sides of the resulting nasal septum are shown in Figure $8 \mathrm{~K}$. In the group administered the caspase inhibitor, the thickness of the OE, total number of OSNs, and the number of supporting cells on the occluded side did not differ from the open side (thickness, $p=$ 0.69 ; number of OSNs, $p=0.72$; number of supporting cells, $p=$ 0.48 ; Mann-Whitney test; Fig. $8 L-N)$. In contrast, DMSO administration during this period induced a thinner $\mathrm{OE}$ and fewer OSNs on the occluded side compared with those on the open side (thickness, $p<0.001$; number of OSNs, $p<0.001$; number of supporting cells, $p=0.89$; Mann-Whitney test; Fig. $8 L-N$ ). These results suggest that the enhanced apoptotic cell death of new neurons under sensory deprivation 7-14 d after injury is a primary factor in the sensory-deprivation-induced incomplete recovery of the $\mathrm{OE}$. Although we cannot rule out the possibility that the survival of the newly generated OSNs by the administration of the caspase inhibitor also compensate for these neural functions, because caspases are also crucial for refinement of mature neuronal circuits (Ohsawa et al., 2010), these results suggest that the survival of the new neurons 7 and $14 \mathrm{~d}$ after injury are involved in the homeostatic regeneration of the $\mathrm{OE}$.

\section{Discussion}

It has been demonstrated in postnatal developing mice that unilateral naris occlusion on day 1 after birth induced a thinner OE,

\section{$\leftarrow$}

(Figure legend continued.) in both the n.0. $\mathrm{d} 0-7$ and n.0. d 7-14 groups. Scale bar, $20 \mu \mathrm{m} . \mathbf{G}$, Number of 0MP-positive cells through the nasal septum in both the n.o. $\mathrm{d} 0-7$ and n.o.d $7-14$ groups. The number of OMP-positive cells in the n.0. $\mathrm{d} 0-7$ group does not differ between the open and the occluded sides, whereas for the n.o. $\mathrm{d} 7-14$ group, the number of OMP-positive cells on the occluded side is significantly bottom than that on the open side ${ }^{* * *} p<0.001$; n.s., not significant; Mann-Whitney test). $\boldsymbol{H}$, Photomicrographs of representative coronal sections from the olfactory nasal septum stained with anti-caspase-3 antibody in both the n.o. $\mathrm{d} 0-7$ and n.0. d 7-14 groups. Arrowheads show caspase-3-positive cells. Scale bar, $20 \mu \mathrm{m}$. I, Number of caspase-3-positive cells in both the n.o. $\mathrm{d} 0-7$ and n.o. $\mathrm{d} 7-14$ groups. The number of caspase-3-positive cells in the open and closed sides of the n.o. $\mathrm{d} 0-7$ group does not change (n.s., not significant; Mann-Whitney test), whereas the number of caspase-3-positive cells on the occluded side is significantly higher than that on the open side in the n.o. $\mathrm{d}$ 7-14 group $\left({ }^{* * *} p<0.001\right.$; Mann-Whitney test). J, Two experimental groups: top, caspase inhibitor administration; bottom, DMSO administration. Both groups of mice received unilateral nostril occlusion 7-14 d after methimazole-induced injury. Mice were administered a caspase inhibitor or DMSO (control) on days 7,9, 11, and 13 after the injury. On day 14 after injury, mice in both groups were perfused with fixative (fixed) for analysis. $\boldsymbol{K}$, Photomicrographs of representative coronal sections from the olfactory nasal septum are shown for both groups (caspase inhibitor administration and DMSO administration). Higher magnification views of the $\mathrm{OE}$ captured from the areas depicted by the squares are illustrated in bottom images. Scale bars, $100 \mu \mathrm{m}$ at lower magnification, $20 \mu \mathrm{m}$ at higher magnification. $\boldsymbol{L}-\boldsymbol{N}$, Thickness of $\mathrm{OE}(\boldsymbol{L})$, number of $0 \mathrm{SNs}(\boldsymbol{M})$, and number of supporting cells $(\boldsymbol{N})$ in groups administered a caspase inhibitor or DMSO. The thickness of the $0 \mathrm{E}$ and number of $\mathrm{OSN}$ s on the occluded side are significantly decreased compared with those on the open side in the group administered DMSO $\left({ }^{* * *} p<0.001\right.$; MannWhitney test), whereas no histological differences were observed between the two sides in the group administered the caspase inhibitor (n.s., not significant; Mann-Whitney test). fewer OSNs, and fewer OMP-positive cells compared with those on the open side by day 12 after occlusion (Coppola et al., 2006). In the present study, we examined in the adult OE whether olfactory sensory deprivation influenced OSN regeneration after the total degeneration of OSNs induced by a methimazole injection. After the methimazole-induced injury, new OSNs were promptly generated from progenitor cells and gradually incorporated into neural circuits within $28 \mathrm{~d}$ (Figs. 2, 9A). However, the postinjury regeneration process was affected by sensory deprivation 14-28 d after injury; the thickness of the OE, number of OSNs, and number of OMP-positive cells all decreased (Figs. 3, 9B). Consistent with the histological observations during this period, we observed an upregulation of apoptosis in immature OSNs (caspase-3-positive cells) and a downregulation of mitosis in OSNs (Ki67-positive cells). The administration of a caspase inhibitor during the regeneration process with sensory deprivation compensated for an incomplete repair of the OE; therefore, the survival of new neurons depends on sensory inputs and neuronal survival is strongly linked to the compensatory regeneration of the $\mathrm{OE}$.

We used the olfactotoxic agent methimazole to reset the cell dynamics of OSNs. The administration of methimazole can induce cell death in OSNs via the mitochondrial cytochrome $c$-mediated caspase-3 activation pathway (Sakamoto et al., 2007). Direct damage resulting from caspase- 3 use is reversible and is thought to be analogous to the type of injury that occurs in a natural condition in which pathogens or toxins are airborne.

From a clinical perspective, olfactory damage, including insults, viral infection, and rhinosinusitis, are serious concerns in humans because they diminish the quality of life and ability to enjoy aromas in daily living. Such pathological olfactory damage inevitably accompanies congestion of the nasal mucosa and frequently induces nostril occlusion. During sensory deprivation, functional replacement of new neurons after olfactory damage may be incomplete despite continuous OSN regeneration (Burd, 1993; Schwob, 2002). Alternatively, if olfactory sensory input is important in the maturation and survival of newly generated OSNs after injury, then an olfactory-enriched environment would facilitate their maturation and survival, leading to functional recovery of the OE after injury (Rochefort et al., 2002; Watt et al., 2004; François et al., 2013). Understanding the molecular and cellular mechanisms that allow new OSNs to develop and mature may lead to establishing novel therapeutic strategies in humans.

\section{Possible mechanisms for incomplete replacement of new OSNs in the sensory-deprived OE}

Neuronal survival depends on neuronal activity (Goldberg and Barres, 2000; François et al., 2013; Park and Poo, 2013; Zhao et al., 2013). Nostril occlusion is a useful method for generating olfactory sensory deprivation and has been used to observe sensory-dependent plasticity in the olfactory system. Temporary nostril occlusion produces a reversible loss of neurons in the OB (Brunjes, 1994; Fiske and Brunjes, 2001), whereas exposure to odorant-enriched environments enhances the neuronal population in the OB (Rochefort et al., 2002). These observations suggest that neural activity may be involved in readjusting the neuronal and synaptic components that allow homeostatic regulation of neural circuit functions (Turrigiano, 2012). We speculate that odor-induced activity has a crucial role in the maturation and survival of new OE neurons and that activity-driven suppression of cell death of immature neurons may be a key factor for the recovery of the $\mathrm{OE}$ and rewiring with the $\mathrm{OB}$. 

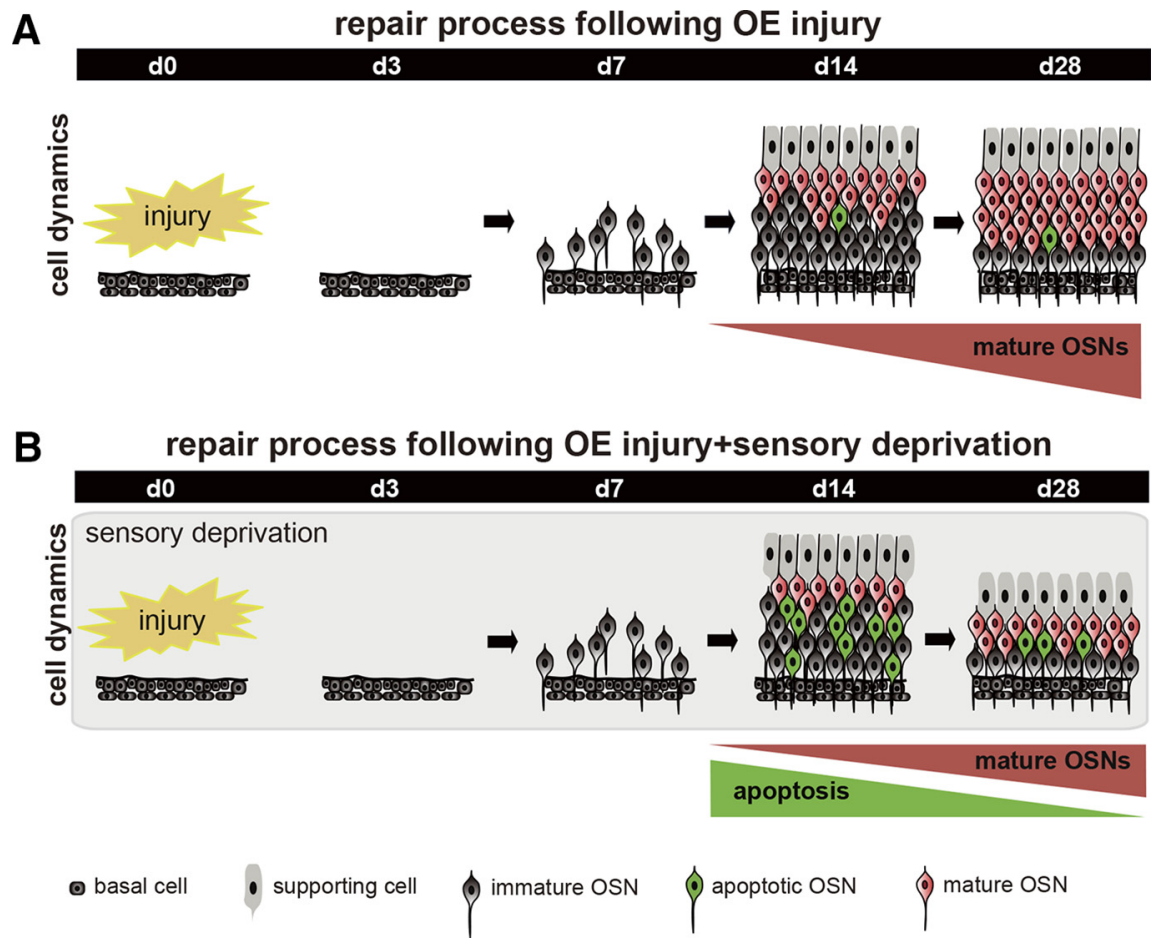

Figure 9. Schematic diagram for sensory-dependent replacement of newly generated OSNs after injury. $\boldsymbol{A}$, Time course for the repair process after injury. Newly generated OSNs are promptly produced after injury and mature during the 7-14 d after injury. Mature OSNs gradually increase and the tissue repair is completed during the $28 \mathrm{~d}$ after injury. $\boldsymbol{B}$, Time course of the repair process after injury and sensory deprivation. During sensory deprivation, newly generated OSNs are highly susceptible to apoptosis while mature OSNs are emerging 7-14 d after injury. As a result of enhanced apoptosis in the immature neurons, $0 \mathrm{E}$ repair by new neurons is incomplete $28 \mathrm{~d}$ after injury.

Previous reports indicate that cAMP-related signaling events mediated via type 3 adenylyl cyclase, mitogen-activated protein kinase, and cAMP response element-binding protein regulate anti-apoptotic genes in the BCL-2 family and enhance development and survival of OSNs (Song and Poo, 1999; Watt et al., 2004; Hyman and Yuan, 2012). In addition, the overexpression of BCL-2 reduced cell death and increased cell numbers in the nervous system, including sympathetic neurons, motor neurons, and retinal ganglion cells (Gagliardini et al., 1994; Martinou et al., 1994). Therefore, it is possible that, during sensory deprivation, an increase in the number of apoptotic cells is due to the downregulation of anti-apoptotic genes in the BCL-2 family.

Extrinsic signals by target $\mathrm{OB}$ neurons may also contribute to the sensory-deprivation-induced increase in apoptosis observed in new OSNs (Burek and Oppenheim, 1996; Jacobson, 1997). Extrinsic signals such as neurotrophins, cytokines, insulin-like growth factor-1, and glial-derived neurotropic factor or its homologs are normally triggered by membrane depolarization through a process mediated by an increase in cytoplasmic $\mathrm{Ca}^{2+}$ and cAMP levels (Balázs et al., 1988; Hack et al., 1993; Blöchl and Thoenen, 1996; Heymach et al., 1996; Abiru et al., 1998; von Bartheld, 1998; Barger, 1999; Griesbeck et al., 1999; Lessmann et al., 2003; Cheng et al., 2011; Park and Poo, 2013). Moreover, synaptic activation of glutamate receptors (particularly NMDA receptors) provides an additional $\mathrm{Ca}^{2+}$ influx that facilitates neurotrophin exocytosis. These signals activate one or more intracellular signaling pathways by binding transmembrane receptors, which in turn inhibit intrinsic apoptosis machinery from conducting a cellular suicide program (Raff, 1992; Burek and Oppenheim, 1996; Frade et al., 1996; Nuñez and del Peso, 1998; Vaux and Korsmeyer, 1999; Pazyra-Murphy et al., 2009). Therefore, during sensory deprivation, decreased neural activity may enhance the intrinsic apoptosis activation pathway and new OSNs fail to establish appropriate synaptic connections, limiting their functional incorporation into neural circuits.

\section{Critical time window for new neurons in the $\mathrm{OE}$}

In the present study, we observed that sensory deprivation 7-14 d after injury affected the recovery of the OE, including the replacement of new OSNs, presumably because of an enhanced apoptotic cell death in new OSNs. This incomplete recovery was compensated for through caspase inhibitor administration. In contrast, a week-long sensory deprivation 0-7 d after injury had little effect. These results indicate that the susceptibility of new OSNs to apoptosis varies according to their maturation stage. We propose that new OSNs have a specific time window (7-14 d after injury) for sensoryinput-dependent survival or death.

Previous reports indicated that newly generated OSNs (double-labeled for the deoxyuridine analog BrdU and OMP) initiate synapses with $\mathrm{OB}$ neurons $7 \mathrm{~d}$ after their birth (Marcucci et al., 2009; Kondo et al., 2010). In addition, the onset of the expression for vesicular glutamate transport protein 2, which is involved in calcium-dependent glutamate release, occurs concomitantly with the onset of the expression of OMP. Consistent with these studies, the present study showed that the emergence of and increase in OMP-positive OSNs occurred 7-14 $\mathrm{d}$ after injury. Furthermore, a majority of adult-born granule cells in the OB 14-20 d after birth synapses with mitral/tufted cells and is susceptible to cell death in a sensory-dependent manner (Yamaguchi and Mori, 2005). The susceptible period of neurons in the rat developing forebrain to drug-induced cell death by chemicals such as ethanol corresponds to the period of their synaptogenesis (Ikonomidou et al., 2000). These considerations raise an intriguing possibility that newly generated OSNs have a critical time window for the formation and maintenance of specific synaptic contacts with $\mathrm{OB}$ neurons. The distinction between survival and death may be executed when OSNs start to interact synaptically with $\mathrm{OB}$ neurons, and this period may correspond to the period of increased susceptibility to sensory-deprivation-dependent apoptosis. Once new OSNs form functional synapses with OB neurons, susceptibility to sensory-deprivation-dependent apoptosis may decrease. Consistent with this idea, sensory deprivation for $28 \mathrm{~d}$ did not affect the histology of the uninjured tissue (Fig. 1). However, whether a long-lasting period of sensory deprivation affects survival of new OSNs remains unclear.

It is tempting to speculate that the critical period is defined by the mechanisms that make caspase activation permissive. A detailed analysis of the positive and negative controls of the apoptotic pathways may provide a clue toward understanding the mechanisms of the critical period for sensory-dependent cell survival and integration of new neurons into preexisting neuronal circuits. 


\section{References}

Abiru Y, Katoh-Semba R, Nishio C, Hatanaka H (1998) High potassium enhances secretion of neurotrophic factors from cultured astrocytes. Brain Res 809:115-126. CrossRef Medline

Balázs R, Jørgensen OS, Hack N (1988) N-methyl-D-aspartate promotes the survival of cerebellar granule cells in culture. Neuroscience 27:437-451. CrossRef Medline

Barger SW (1999) Complex influence of the L-type calcium-channel agonist BayK8644(+/-) on N-methyl-D-aspartate responses and neuronal survival. Neuroscience 89:101-108. CrossRef Medline

Blöchl A, Thoenen H (1996) Localization of cellular storage compartments and sites of constitutive and activity-dependent release of nerve growth factor (NGF) in primary cultures of hippocampal neurons. Mol Cell Neurosci 7:173-190. CrossRef Medline

Brunjes PC (1994) Unilateral naris closure and olfactory system development. Brain Res Brain Res Rev 19:146-160. CrossRef Medline

Burd GD (1993) Morphological study of the effects of intranasal zinc sulfate irrigation on the mouse olfactory epithelium and olfactory bulb. Microsc Res Tech 24:195-213. CrossRef Medline

Burek MJ, Oppenheim RW (1996) Programmed cell death in the developing nervous system. Brain Pathol 6:427-446. CrossRef Medline

Cheng PL, Song AH, Wong YH, Wang S, Zhang X, Poo MM (2011) Selfamplifying autocrine actions of BDNF in axon development. Proc Natl Acad Sci U S A 108:18430-18435. CrossRef Medline

Coppola DM, Waguespack AM, Reems MR, Butman ML, Cherry JA (2006) Naris occlusion alters transductory protein immunoreactivity in olfactory epithelium. Histol Histopathol 21:487-501. Medline

Cummings DM, Henning HE, Brunjes PC (1997) Olfactory bulb recovery after early sensory deprivation. J Neurosci 17:7433-7440. Medline

Ekdahl CT, Claasen JH, Bonde S, Kokaia Z, Lindvall O (2003) Inflammation is detrimental for neurogenesis in adult brain. Proc Natl Acad Sci U S A 100:13632-13637. CrossRef Medline

Farbman AI, Brunjes PC, Rentfro L, Michas J, Ritz S (1988) The effect of unilateral naris occlusion on cell dynamics in the developing rat olfactory epithelium. J Neurosci 8:3290-3295. Medline

Fiske BK, Brunjes PC (2001) Cell death in the developing and sensorydeprived rat olfactory bulb. J Comp Neurol 431:311-319. Medline

Frade JM, Rodríguez-Tébar A, Barde YA (1996) Induction of cell death by endogenous nerve growth factor through its p75 receptor. Nature 383: 166-168. CrossRef Medline

François A, Laziz I, Rimbaud S, Grebert D, Durieux D, Pajot-Augy E, Meunier N (2013) Early survival factor deprivation in the olfactory epithelium enhances activity-driven survival. Front Cell Neurosci 7:271. Medline

Gagliardini V, Fernandez PA, Lee RK, Drexler HC, Rotello RJ, Fishman MC, Yuan J (1994) Prevention of vertebrate neuronal death by the crmA gene. Science 263:826-828. CrossRef Medline

Goldberg JL, Barres BA (2000) The relationship between neuronal survival and regeneration. Annu Rev Neurosci 23:579-612. CrossRef Medline

Griesbeck O, Canossa M, Campana G, Gärtner A, Hoener MC, Nawa H, Kolbeck R, Thoenen H (1999) Are there differences between the secretion characteristics of NGF and BDNF? Implications for the modulatory role of neurotrophins in activity-dependent neuronal plasticity. Microsc Res Tech 45:262-275. CrossRef Medline

Hack N, Hidaka H, Wakefield MJ, Balázs R (1993) Promotion of granule cell survival by high $\mathrm{K}+$ or excitatory amino acid treatment and $\mathrm{Ca} 2+$ / calmodulin-dependent protein kinase activity. Neuroscience 57:9-20. CrossRef Medline

Heymach JV Jr, Krüttgen A, Suter U, Shooter EM (1996) The regulated secretion and vectorial targeting of neurotrophins in neuroendocrine and epithelial cells. J Biol Chem 271:25430-25437. CrossRef Medline

Hyman BT, Yuan J (2012) Apoptotic and non-apoptotic roles of caspases in neuronal physiology and pathophysiology. Nat Rev Neurosci 13:395406. Medline

Ikonomidou C, Bittigau P, Ishimaru MJ, Wozniak DF, Koch C, Genz K, Price MT, Stefovska V, Hörster F, Tenkova T, Dikranian K, Olney JW (2000) Ethanol-induced apoptotic neurodegeneration and fetal alcohol syndrome. Science 287:1056-1060. CrossRef Medline

Jacobson MD (1997) Programmed cell death: a missing link is found. Trends Cell Biol 7:467-469. CrossRef Medline

Jin BK, Franzen L, Baker H (1996) Regulation of c-Fos mRNA and fos protein expression in olfactory bulbs from unilaterally odor-deprived adult mice. Int J Dev Neurosci 14:971-982. CrossRef Medline
Kikuta S, Kashiwadani H, Mori K (2008) Compensatory rapid switching of binasal inputs in the olfactory cortex. J Neurosci 28:11989-11997. CrossRef Medline

Kikuta S, Sato K, Kashiwadani H, Tsunoda K, Yamasoba T, Mori K (2010) From the Cover: Neurons in the anterior olfactory nucleus pars externa detect right or left localization of odor sources. Proc Natl Acad Sci U S A 107:12363-12368. CrossRef Medline

Kikuta S, Fletcher ML, Homma R, Yamasoba T, Nagayama S (2013) Odorant response properties of individual neurons in an olfactory glomerular module. Neuron 77:1122-1135. CrossRef Medline

Kobayakawa K, Kobayakawa R, Matsumoto H, Oka Y, Imai T, Ikawa M, Okabe M, Ikeda T, Itohara S, Kikusui T, Mori K, Sakano H (2007) Innate versus learned odour processing in the mouse olfactory bulb. Nature 450:503-508. CrossRef Medline

Kondo K, Suzukawa K, Sakamoto T, Watanabe K, Kanaya K, Ushio M, Yamaguchi T, Nibu K, Kaga K, Yamasoba T (2010) Age-related changes in cell dynamics of the postnatal mouse olfactory neuroepithelium: cell proliferation, neuronal differentiation, and cell death. J Comp Neurol 518: 1962-1975. CrossRef Medline

Lessmann V, Gottmann K, Malcangio M (2003) Neurotrophin secretion: current facts and future prospects. Prog Neurobiol 69:341-374. CrossRef Medline

Marcucci F, Zou DJ, Firestein S (2009) Sequential onset of presynaptic molecules during olfactory sensory neuron maturation. J Comp Neurol 516: 187-198. CrossRef Medline

Martinou JC, Dubois-Dauphin M, Staple JK, Rodriguez I, Frankowski H, Missotten M, Albertini P, Talabot D, Catsicas S, Pietra C, Huarte J (1994) Overexpression of BCL-2 in transgenic mice protects neurons from naturally occurring cell death and experimental ischemia. Neuron 13:10171030. CrossRef Medline

Maruniak JA, Lin PJ, Henegar JR (1989) Effects of unilateral naris closure on the olfactory epithelia of adult mice. Brain Res 490:212-218. CrossRef Medline

Maruniak JA, Henegar JR, Sweeney TP (1990) Effects of long-term unilateral naris closure on the olfactory epithelia of adult mice. Brain Res 526: 65-72. CrossRef Medline

Meister M, Bonhoeffer T (2001) Tuning and topography in an odor map on the rat olfactory bulb. J Neurosci 21:1351-1360. Medline

Monje ML, Toda H, Palmer TD (2003) Inflammatory blockade restores adult hippocampal neurogenesis. Science 302:1760-1765. CrossRef Medline

Mori K, Sakano H (2011) How is the olfactory map formed and interpreted in the mammalian brain? Annu Rev Neurosci 34:467-499. CrossRef Medline

Nuñez G, del Peso L (1998) Linking extracellular survival signals and the apoptotic machinery. Curr Opin Neurobiol 8:613-618. CrossRef Medline

Ohsawa S, Hamada S, Kuida K, Yoshida H, Igaki T, Miura M (2010) Maturation of the olfactory sensory neurons by Apaf-1/caspase-9-mediated caspase activity. Proc Natl Acad Sci U S A 107:13366-13371. CrossRef Medline

Olney JW, Tenkova T, Dikranian K, Muglia LJ, Jermakowicz WJ, D'Sa C, Roth KA (2002) Ethanol-induced caspase-3 activation in the in vivo developing mouse brain. Neurobiol Dis 9:205-219. CrossRef Medline

Park H, Poo MM (2013) Neurotrophin regulation of neural circuit development and function. Nat Rev Neurosci 14:7-23. CrossRef Medline

Pazyra-Murphy MF, Hans A, Courchesne SL, Karch C, Cosker KE, Heerssen HM, Watson FL, Kim T, Greenberg ME, Segal RA (2009) A retrograde neuronal survival response: target-derived neurotrophins regulate MEF2D and bcl-w. J Neurosci 29:6700-6709. CrossRef Medline

Raff MC (1992) Social controls on cell survival and cell death. Nature 356: 397-400. CrossRef Medline

Rochefort C, Gheusi G, Vincent JD, Lledo PM (2002) Enriched odor exposure increases the number of newborn neurons in the adult olfactory bulb and improves odor memory. J Neurosci 22:2679-2689. Medline

Sakamoto T, Kondo K, Kashio A, Suzukawa K, Yamasoba T (2007) Methimazole-induced cell death in rat olfactory receptor neurons occurs via apoptosis triggered through mitochondrial cytochrome c-mediated caspase-3 activation pathway. J Neurosci Res 85:548-557. CrossRef Medline

Schwob JE (2002) Neural regeneration and the peripheral olfactory system. Anat Rec 269:33-49. CrossRef Medline 
Song HJ, Poo MM (1999) Signal transduction underlying growth cone guidance by diffusible factors. Curr Opin Neurobiol 9:355-363. CrossRef Medline

Stahl B, Distel H, Hudson R (1990) Effects of reversible nare occlusion on the development of the olfactory epithelium in the rabbit nasal septum. Cell Tissue Res 259:275-281. CrossRef Medline

Suh KS, Kim SY, Bae YC, Ronnett GV, Moon C (2006) Effects of unilateral naris occlusion on the olfactory epithelium of adult mice. Neuroreport 17:1139-1142. CrossRef Medline

Tsuboi A, Miyazaki T, Imai T, Sakano H (2006) Olfactory sensory neurons expressing class I odorant receptors converge their axons on an anterodorsal domain of the olfactory bulb in the mouse. Eur J Neurosci 23: 1436-1444. CrossRef Medline

Turrigiano G (2012) Homeostatic synaptic plasticity: local and global mechanisms for stabilizing neuronal function. Cold Spring Harb Perspect Biol 4:a005736. Medline

Uchida N, Takahashi YK, Tanifuji M, Mori K (2000) Odor maps in the mammalian olfactory bulb: domain organization and odorant structural features. Nat Neurosci 3:1035-1043. CrossRef Medline

Vaux DL, Korsmeyer SJ (1999) Cell death in development. Cell 96:245-254. CrossRef Medline

von Bartheld CS (1998) Neurotrophins in the developing and regenerating visual system. Histol Histopathol 13:437-459. Medline

Watt WC, Sakano H, Lee ZY, Reusch JE, Trinh K, Storm DR (2004) Odorant stimulation enhances survival of olfactory sensory neurons via MAPK and CREB. Neuron 41:955-967. CrossRef Medline

Yamaguchi M, Mori K (2005) Critical period for sensory experience-dependent survival of newly generated granule cells in the adult mouse olfactory bulb. Proc Natl Acad Sci U S A 102:9697-9702. CrossRef Medline

Yuan J, Lipinski M, Degterev A (2003) Diversity in the mechanisms of neuronal cell death. Neuron 40:401-413. CrossRef Medline

Zhao S, Tian H, Ma L, Yuan Y, Yu CR, Ma M (2013) Activity-dependent modulation of odorant receptor gene expression in the mouse olfactory epithelium. PLoS One 8:e69862. CrossRef Medline 